Article

\title{
Evaluating Carbon Monoxide and Aerosol Optical Depth Simulations from CAM-Chem Using Satellite Observations
}

\author{
Débora Souza Alvim ${ }^{1,2}, *$, Júlio Barboza Chiquetto ${ }^{3}\left({ }^{\circ}\right.$, Monica Tais Siqueira D'Amelio ${ }^{4}\left({ }^{\circ}\right.$, Bushra Khalid ${ }^{5,6,7}$, \\ Dirceu Luis Herdies ${ }^{1}{ }^{10}$, Jayant Pendharkar ${ }^{1}$, Sergio Machado Corrêa ${ }^{8}$, Silvio Nilo Figueroa ${ }^{1}$, Ariane Frassoni ${ }^{1}$, \\ Vinicius Buscioli Capistrano ${ }^{9}$, Claudia Boian ${ }^{10}$, Paulo Yoshio Kubota ${ }^{1}$ and Paulo Nobre ${ }^{1}$
}

1 Center for Weather Forecasting and Climate Studies (CPTEC), National Institute for Space Research (INPE), Cachoeira Paulista 12630-000, SP, Brazil; dirceu.herdies@inpe.br (D.L.H.); jayant.pendharkar@inpe.br (J.P.); nilo.figueroa@inpe.br (S.N.F.); ariane.frassoni@inpe.br (A.F.); paulo.kubota@inpe.br (P.Y.K.); paulo.nobre@inpe.br (P.N.)

2 Lorena School of Engineering (EEL), University of Sao Paulo (USP), Lorena 05508-050, SP, Brazil

3 Institute of Advanced Studies, University of Sao Paulo (USP), São Paulo 05508-050, SP, Brazil; julio22@usp.br

4 Research Group on Environment and Sustainability (GPMAS), University of São Francisco (USF), Itatiba 13250-400, SP, Brazil; monica.felippe@usf.edu.br

5 Institute of Geographic Sciences and Natural Resources Research, Chinese Academy of Sciences, Beijing 100101, China; khalid@iiasa.ac.at

6 Department of Environmental Sciences, International Islamic University, Islamabad 44000, Pakistan

7 Earth System Physics, Abdus Salam International Centre for Theoretical Physics, 34151 Trieste, Italy

check for

updates

Citation: Alvim, D.S.; Chiquetto, J.B.; D'Amelio, M.T.S.; Khalid, B.; Herdies, D.L.; Pendharkar, J.; Corrêa, S.M.;

Figueroa, S.N.; Frassoni, A.;

Capistrano, V.B.; et al. Evaluating

Carbon Monoxide and Aerosol

Optical Depth Simulations from CAM-Chem Using Satellite Observations. Remote Sens. 2021, 13, 2231. https://doi.org/10.3390/ rs13112231

Academic Editor: Simone Lolli

Received: 18 April 2021

Accepted: 31 May 2021

Published: 7 June 2021

Publisher's Note: MDPI stays neutral with regard to jurisdictional claims in published maps and institutional affiliations.

Copyright: (c) 2021 by the authors. Licensee MDPI, Basel, Switzerland. This article is an open access article distributed under the terms and conditions of the Creative Commons Attribution (CC BY) license (https:// creativecommons.org/licenses/by/ $4.0 /)$.
8 Faculty of Technology, Rio de Janeiro State University, Resende 27537-000, RJ, Brazil; sergiomc@uerj.br

9 Institute of Physics, Federal University of Mato Grosso do Sul, Campo Grande 79070-900, MS, Brazil; vinicius.capistrano@ufms.br

10 Center for Engineering, Modeling and Applied Social Sciences (CECS), Federal University of ABC (UFABC), Santo André 09210-580, SP, Brazil; claudia.boian@ufabc.edu.br

* Correspondence: debora.alvim@inpe.br or deborasalvim@gmail.com
Abstract: The scope of this work was to evaluate simulated carbon monoxide (CO) and aerosol optical depth (AOD) from the CAM-chem model against observed satellite data and additionally explore the empirical relationship of $\mathrm{CO}, \mathrm{AOD}$ and fire radiative power (FRP). The simulated seasonal global concentrations of $\mathrm{CO}$ and AOD were compared, respectively, with the Measurements of Pollution in the Troposphere (MOPITT) and the Moderate-Resolution Imaging Spectroradiometer (MODIS) satellite products for the period 2010-2014. The CAM-chem simulations were performed with two configurations: (A) tropospheric-only; and (B) tropospheric with stratospheric chemistry. Our results show that the spatial and seasonal distributions of $\mathrm{CO}$ and AOD were reasonably reproduced in both model configurations, except over central China, central Africa and equatorial regions of the Atlantic and Western Pacific, where CO was overestimated by 10-50 ppb. In configuration B, the positive $\mathrm{CO}$ bias was significantly reduced due to the inclusion of dry deposition, which was not present in the model configuration $\mathrm{A}$. There was greater $\mathrm{CO}$ loss due to the chemical reactions, and shorter lifetime of the species with stratospheric chemistry. In summary, the model has difficulty in capturing the exact location of the maxima of the seasonal AOD distributions in both configurations. The AOD was overestimated by 0.1 to 0.25 over desert regions of Africa, the Middle East and Asia in both configurations, but the positive bias was even higher in the version with added stratospheric chemistry. By contrast, the AOD was underestimated over regions associated with anthropogenic activity, such as eastern China and northern India. Concerning the correlations between CO, AOD and FRP, high CO is found during March-April-May (MAM) in the Northern Hemisphere, mainly in China. In the Southern Hemisphere, high CO, AOD, and FRP values were found during AugustSeptember-October (ASO) due to fires, mostly in South America and South Africa. In South America, high AOD levels were observed over subtropical Brazil, Paraguay and Bolivia. Sparsely urbanized regions showed higher correlations between CO and FRP (0.7-0.9), particularly in tropical areas, such as the western Amazon region. There was a high correlation between $\mathrm{CO}$ and aerosols from biomass burning at the transition between the forest and savanna environments over eastern and central Africa. It was also possible to observe the transport of these pollutants from the African continent to 
the Brazilian coast. High correlations between $\mathrm{CO}$ and AOD were found over southeastern Asian countries, and correlations between FRP and AOD (0.5-0.8) were found over higher latitude regions such as Canada and Siberia as well as in tropical areas. Higher correlations between CO and FRP are observed in Savanna and Tropical forests (South America, Central America, Africa, Australia, and Southeast Asia) than FRP x AOD. In contrast, boreal forests in Russia, particularly in Siberia, show a higher FRP x AOD correlation than FRP x CO. In tropical forests, CO production is likely favored over aerosol, while in temperate forests, aerosol production is more than CO compared to tropical forests. On the east coast of the United States, the eastern border of the USA with Canada, eastern China, on the border between China, Russia, and Mongolia, and the border between North India and China, there is a high correlation of CO x AOD and a low correlation between FRP with both CO and AOD. Therefore, such emissions in these regions are not generated by forest fires but by industries and vehicular emissions since these are densely populated regions.

Keywords: carbon monoxide; aerosol optical depth; FRP; MOPITT; MODIS; CAM-chem

\section{Introduction}

In the last decade, studies have shown that one of the consequences of climate change is the intensification of anthropogenic fires, which lead to changes in land cover, mainly in forested regions. Such activity is considered an important source of greenhouse gases, aerosols and pollutants to the atmosphere. Fires produce extensive plumes of smoke, mainly in the dry season [1,2]. This is alarming in the sense that significant changes in atmospheric composition and air quality may occur [3], which can be studied by using remote sensing data. However, these data are still underexplored in air quality studies over the southern hemisphere, although there is great potential here as some environmental satellites (Aqua and Terra) allow the monitoring of the concentration of pollutants with sensors such as Measurements of Pollution in the Troposphere (MOPITT) and ModerateResolution Imaging Spectroradiometer (MODIS).

Global monitoring surveys using satellites can be used to determine the sources of concentration of $\mathrm{CO}, \mathrm{NO}_{2}, \mathrm{O}_{3}$, formaldehyde, aerosols and other pollutants, demonstrating the great potential for the analysis of air pollution. Lacking aerosol optical depth (AOD) and $\mathrm{CO}$ concentration measurements on the surface and even at altitude can be complemented by using global remote information obtained through sounders onboard environmental satellites. Studies such as those presented in [4,5] show the advantage of using information from the environmental satellite MODIS (Aqua and Terra) to detect and monitor the concentration of gases.

On the other hand, the biogeochemical cycles are influenced by anthropogenic and natural activities. Therefore, it is important to understand these influences by monitoring the temporal and spatial distribution of gases, identifying the source and sink origins. Carbon monoxide (CO) is present in the atmosphere, has roughly a 2-month lifetime and diverse natural and anthropogenic sources, such as methane $\left(\mathrm{CH}_{4}\right)$ oxidation, nonmethane hydrocarbons (NMHC) oxidation, biomass burning, fossil fuel burning, etc. CO affects the hydroxyl radical $(\mathrm{OH})$, so it influences tropospheric chemistry. Its sources are essentially anthropogenic (500-600 $\mathrm{Tg} \mathrm{yr}^{-1}$ ) and biomass burning (300-600 $\mathrm{Tg} \mathrm{yr}^{-1}$ ), both with a significant annual variation. For these and other reasons, $\mathrm{CO}$ is used as a transport tracer [6,7]. Biomass burning is considered a relevant source of trace gases and particulate matter (mainly composed of organic and black carbon substances) to the atmosphere [8].

On a regional scale, the influence of biomass burning is also significant in Africa [9,10], South America [11,12], northwest America [13], East Asia [14], Southeast Asia [15], Australia [16] and Russia [17]. The combustion process of the biomass under ideal conditions 
of complete combustion releases carbon dioxide $\left(\mathrm{CO}_{2}\right)$ and water vapor $\left(\mathrm{H}_{2} \mathrm{O}\right)$ into the atmosphere, according to Equation (1) [18]:

$$
\mathrm{CH}_{2} \mathrm{O}+\mathrm{O}_{2} \rightarrow \mathrm{CO}_{2}+\mathrm{H}_{2} \mathrm{O},
$$

where $\mathrm{CH}_{2} \mathrm{O}$ represents the plant biomass; however, complete combustion during biomass burning usually does not happen. It is common to find other species of gases constituted by carbon molecules such as carbon monoxide $(\mathrm{CO})$, methane $\left(\mathrm{CH}_{4}\right)$, non-methane hydrocarbons (NMHC) and suspended carbon particles (C). In addition to these gases, nitrogen oxides $(\mathrm{NOx})$, methyl chloride $\left(\mathrm{CH}_{3} \mathrm{Cl}\right)$, sulfur dioxide $\left(\mathrm{SO}_{2}\right)$ and other species are produced in the combustion process [19]. Trace gases and aerosols released during biomass burning are mainly composed of oxidized organic materials. They have molecular properties that interact with the electromagnetic radiation (EMR) in the atmosphere, causing absorption and/or scattering. The interactions of these radiatively active compounds with EMR, along with changes in the Earth's surface properties, cause significant changes in latent and sensible heat fluxes, biogeochemical cycles and cloud nucleation [20].

The fire radiative power (FRP) is used to relate the total emissions of trace gases and aerosols injected into the atmosphere by the occurrence of fires. FRP is proportional to the amount of biomass consumed in the burning process and can be considered to be an indicator of trace gases and particulate matter emitted to the atmosphere due to biomass burning [21]. The first studies on FRP used MODIS Airborne Simulator (MAS) in the Smoke, Cloud and Radiation, Brazil/California experiments (SCAR-B and SCAR-C, respectively), presented in [22,23], used a semi-empirical relationship between the FRP and infrared spectral radiance. It used MODIS band 21 centered at $4 \mu \mathrm{m}$, associating the FRP with the pixel brightness temperature $\left(T_{\mathrm{f} 4 \mu \mathrm{m}}\right)$ and the background temperature $\left(\boldsymbol{T}_{\mathrm{b} 4 \mu \mathrm{m}}\right)$ of the respective bands. A total emitted power value was assigned to each fire pixel. The total emitted power was deemed a proper quantity in the estimation of fire emissions [23]. A relationship between the rate of emitted energy, $\boldsymbol{E}_{f}$, and the detected temperature difference in the $4 \mu \mathrm{m}$ channel is approximated by Equation (2) [22,23], and Equation (3) represents the FRP obtained through the MODIS sensor.

$$
\begin{gathered}
E_{f}=K\left(T_{\mathrm{f} 4 \mu \mathrm{m}}-T_{\mathrm{b} 4 \mu \mathrm{m}}\right) \\
F R P=E f * \text { Asampl }
\end{gathered}
$$

where $K$ is a constant $\left(4.3 \times 10^{-19}\right), E_{f}$ is the rate of emitted energy $\left(\mathrm{W} / \mathrm{m}^{2}\right.$ or equivalently, MW per pixel) and Asampl represents the size of the pixel area $\left(\mathrm{km}^{2}\right)$.

Trace gases and the direct and indirect effects of aerosols can affect the energy balance of the atmosphere. Fires, which occur mainly in tropical areas of the planet, are important sources of pollutants to the atmosphere [8,24]. During the winter months, hundreds of thousands of fire outbreaks occur in the tropical regions, mainly in savanna and forest ecosystems. During the combustion of biomass, gases, including some greenhouse gases and precursors of tropospheric ozone, are emitted into the atmosphere, and aerosol particles that interact efficiently with solar radiation and affect the processes of microphysics and cloud formation dynamics and the quality of air. Therefore, the effects of these emissions exceed the local scale and regionally affect the composition and physical and chemical properties of the atmosphere and neighboring ocean areas, with potential impact on a global scale.

On regional and global scales, these emissions from fires alter the radiative balance of the atmosphere through the direct effects of aerosol particles by reflecting and spreading solar radiation back into space, reducing the amount absorbed by the Earth's surface, and by absorbing solar radiation, heating the atmosphere. [25] suggests that atmospheric heating due to aerosols of the black carbon type could balance the cooling effect associated with other types (sulfates), and that their direct radiative forcing may exceed that associated 
with $\mathrm{CH}_{4}$. In this way, aerosol particles, the product of incomplete combustion processes, would be second only to $\mathrm{CO}_{2}$ in the contribution to the radiative heating of the atmosphere.

The radiation balance and the hydrological cycle can also be indirectly affected by the emissions from fires, via changes in microphysics and the dynamics of cloud formation, due to greater availability of cloud condensation nuclei $(\mathrm{CCN})$ and ice in the atmosphere, which promotes changes in the cloud droplet spectra $[1,26,27]$ and thermodynamic stabilization [21]. The increase in the concentration of aerosol particles imposes the production of smaller and greater cloud droplets, producing two effects: first, the greater amount of droplets reflects more solar radiation back into space (thus cooling the atmosphere), and, second, the smaller size will be less favorable for rain production, as very small droplets do not tend to clump together to form the large drops that fall like rain. On the other hand, the thermodynamic stabilization imposed by the direct interaction of aerosol particles with solar radiation (decreases heating in the lower atmosphere by reducing solar radiation) restricts the rise of convective cells generated close to the surface and, thus, inhibits the formation of clouds. This set of factors suggests that the effects of fires can go beyond the local scale and significantly affect the hydrological cycle on a regional scale and the pattern of planetary redistribution of energy from the tropics to mid and high latitudes.

On the other hand, changes in land use cause changes in the energy, water and momentum balances on the surface, due to the corresponding changes in the surface albedo and evapotranspiration capacity associated with the vegetation cover and its spatial structure. In particular, the replacement of forested areas with a deep root system by pasture areas implies an increase in albedo and low accessibility to deep soils with high water storage. This change generally leads to an inversion in Bowen's ratio, producing drier, hotter and deeper planetary boundary layers, mainly during the dry season.

Another relevant and little-studied aspect corresponds to the effect of land-use change on dust aerosols. With more exposed soils and more intense winds (which is expected with the reduction of the roughness of the land when exchanging forests for pastures) there may be a significant increase in the production and lifting of soil dust, which also impacts the radioactive balance, cloud microphysics and hydrological cycle.

Thus, changes in land use are, by themselves, inducing changes in the pattern of the hydrological cycle and these changes can be evaluated using numerical models and land occupation scenarios. Therefore, this is crucial for their adequate representation in weather forecasting and climate models. Furthermore, the assimilation of trace gases and aerosol emissions was carried out to improve weather forecasts and climate modeling [28-30]. The gases and aerosols emitted in the combustion process alter the incidence of solar radiation significantly. Consequently, the radiation and water budgets, cloud microphysics and chemical composition of the atmosphere are influenced by aerosols and gases [31]. Besides, these particles and gases have significant impacts on public health.

The damages to health and the absence of barriers for this type of contaminant in the air justify the concern regarding the identification of these pollutants in the atmosphere. Pollution emitted by a particular country or locality is not restricted to that location and can cause damage beyond its borders. According to the World Health Organization (WHO), $92 \%$ of the world's population lives in places where air quality levels exceed the limits established by the WHO. Three million deaths per year are reported due to exposure to air pollution in external environments. Of these, $90 \%$ occur in low and middle-income countries [32]. The Global Burden of Disease 2015 Study (GBD 2015) showed that air pollution was directly linked to $19 \%$ of deaths from cardiovascular diseases worldwide, $21 \%$ from stroke deaths or cerebrovascular accident, $23 \%$ from lung cancer and $24 \%$ from ischemic heart diseases [32].

Given the importance of these particles and gases in the atmospheric energy balance and for public health, our goal was to determine how well the global chemical models simulate these aerosol and trace gases compared to satellite observations. For that purpose, we chose one of the most popular global models, the Community Atmosphere Model with chemistry (CAM-chem). Two sets of CAM-chem simulations were performed: tropospheric- 
only and tropospheric with stratospheric chemistry included. Thus, this research aims to evaluate the seasonal global representation of $\mathrm{CO}$ and AOD simulated by the CAMchem model against observed satellite data. Finally, since $43 \%$ of inhalable particulate matter $\left(\mathrm{PM}_{10}\right)$ and $41 \%$ of fine particulate matter $\left(\mathrm{PM}_{2.5}\right)$ are emitted by forest and savanna fires [33], we analyzed the seasonality of FRP and explored the observational relationship between CO, AOD and FRP during the period 2010-2014.

This paper is organized as follows: Section 2 describes the dataset and model configurations. Sections 3.1-3.3 describe the comparative study of CAM-chem-simulated CO and AOD against the remote sensing products from the satellite observational data. Section 3.4 shows the correlations between global FRP, CO and AOD for the period studied. Finally, Section 4 presents our conclusions.

\section{Materials and Methods}

\subsection{Satellite Data}

\subsubsection{CO from MOPITT}

In this work, a priori gridded CO monthly data from Level 3 version 8 (V8) of the Measurement of Pollution in the Troposphere (MOPITT) based on simultaneous thermal-infrared (TIR) and near-infrared (NIR) products with a mixing ratio of $1000 \mathrm{hPa}$ is used $[34,35]$. The TIR-NIR product offers the greatest vertical resolution and considerable sensitivity to $\mathrm{CO}$ in the lower troposphere.

MOPITT is one of five remote sensing instruments on the satellite Terra, launched by NASA in December 1999. The basic operation of the MOPITT involves an infrared radiometer in which the gas cell is used as an optical filter to measure the signal from the same gas in the atmosphere. It combines scanning actinography and meteorological spectrography to measure the resurgent thermal emission of $\mathrm{CO}$ and $\mathrm{CH}_{4}$ in thermal channels. MOPITT is in orbit at $705 \mathrm{~km}$ altitude; the satellite passes over a given region every 16 days, providing a near-complete global coverage every 3-4 days [36-39].

The MOPITT Level 3 data set provides global coverage of: (1) the total amount of CO in the column, (2) the CO mixing ratio at seven altitudes $(1000,850,700,500,350,250$ and $150 \mathrm{hPa}$ ), and (3) the view and time along the track. It has a horizontal resolution of $22 \mathrm{~km}$ and vertical resolution of $3 \mathrm{~km}$, with an average accuracy of $10 \%$. These data were validated and extensively described by [35]. We studied the spatial and temporal distribution of CO concentrations around the globe from 2010-2014 using MOPITT a priori gridded CO data (variable a priori CO surface mixing ratio day_MOP03), which has a spatial resolution of $1^{\circ} \times 1^{\circ}$. A correction of bias in the geolocation data in the previous iteration of MOPITT was introduced in V8. V8 retrieval processing utilizes Modern-Era Retrospective analysis for Research and Applications-2 (MERRA-2) reanalysis as the meteorological data source, offering an improved spatial resolution for atmospheric variables. Therefore, meteorological data required for Level 2 processing (specifically, water vapor, temperature profiles and surface skin temperature) are based on the MERRA-2 reanalysis product. MOPITT provides observations during the daytime and nighttime, which are processed separately with Level 3 processing (based on solar zenith angle), yielding separate daytime and nighttime products within each Level 3 HDF file (c.f., $[35,40,41])$. Notably, overland, the a priori sensitivity is generally higher for daytime overpasses than for nighttime overpasses $[42,43]$. This work uses the V8 TIR-NIR a priori surface-level daytime CO.

\subsubsection{FRP from MODIS}

In this work, we used the monthly FRP data from the MODIS/Aqua 1-degree gridded MODIS Active Fire Product V005 (MYD14CM1)—Thermal Anomalies/Fire products, which were estimated by the MODIS sensor with the AQUA platform with $1 \mathrm{~km}$ of spatial resolution from January 2010 to December 2014. The gridded MODIS active fire products present statistical summaries of fire pixel information.

The global monthly products were generated at a $1^{\circ} \times 1^{\circ}$ spatial resolution for the time of one calendar month. These products were derived from MODIS Climate Modeling 
Grid (CMG) $0.5^{\circ}$ products (c.f., [44]) for the Northern Eurasia Earth Science Partnership Initiative (NEESPI) program, which were used in support of research on surface processes and climate modeling. There are 36 discrete spectral bands of the MODIS that observe the globe at each point every 1-2 days. The Terra AM (10:30 and 22:30) and Aqua PM (13:30 and 01:30) platforms record fire observations four times a day. The resolution of MODIS fire products is $1 \mathrm{~km}$, recorded at 3.9 and $11 \mu \mathrm{m}$. The pre-launch calibration of the high-gain channels is improved by post-launch remote calibration due to the lack of on-board calibration of high-temperature sensors. The MODIS fire products based on heritage algorithms used with Advanced Very-High-Resolution Radiometer (AVHRR) and Geostationary Operational Environmental Satellite (GOES) sensors provide information for operational fire monitoring. MODIS provides information on emitted energy, the estimation of burned area, fire location and the smoldering and flaming ratio. MODIS algorithms, including the fire algorithm, are updated periodically, leading to different versions and generating a series of data set products [44,45].

Spaceborne instruments provide a unique view of global vegetation fire activity many times a day. In this study, we assessed the fire characterization information provided by the Aqua MODIS Thermal Anomalies product (MYD14) for FRP seasonal averages from 2010 to 2014. The detection limit for MYD14 (Aqua) is approximately 9 MW, and that for MOD14 (Terra) is 11 MW. In [46], a positive correlation was found between the FRP and the percentage of vegetation cover, indicating that the FRP is sensitive to biomass density.

\subsubsection{AOD from MODIS}

Satellite observations of AOD were obtained from MODIS using radiometers with 36 bands ranging between $0.4 \mu \mathrm{m}$ and $14.4 \mu \mathrm{m}$ on the Terra and Aqua satellites of NASA $[47,48]$. In $[46,49]$, the authors used AOD data from MODIS Aqua and Terra sensors. The combined ocean/land algorithm takes advantage of the wide spectral range and high spatial resolution of MODIS with daily global coverage (e.g., $500 \mathrm{~m}$ at 0.47 to $2.12 \mu \mathrm{m}$ with $250 \mathrm{~m}$ at 0.66 and $0.86 \mu \mathrm{m}$ and $1 \mathrm{~km}$ at $1.38 \mu \mathrm{m}$ ). The newest MODIS Collection 6.1 (C6.1) AOD products with various refinements and improvements made to both the radiation calibration and Dark Target (DT) and Deep Blue (DB) algorithms are available. These products have been validated against ground observations (e.g., [50-54]).

Reference [50] validated the newest MODIS Collection 6.1 AOD products over land and ocean against ground based AOD data from the latest version (Version 3 Level 2.0) data derived from AERONET ground measurements observed at 384 sites to gain a knowledge of their accuracy and problems at global, regional, and individual site scales. They discussed the validations for high vegetation and low aerosol loading in Europe, eastern North America, and Southeast Asia. They found that in general C6.1 aerosol products improved in comparison to C6 products on local, regional and global scales. [51] provides a comprehensive validation and error analysis of the MOD04_3K C6.1 AOD data set against AERONET Version 3 measurements at different space-time scales from 2013 to 2017 on the land and the ocean. Their results suggest that the data quality of the MOD04_3K AOD data set is globally improved at different spatial scales after quality control. Many studies have been carried out comparing products from different versions of MODIS against AERONET data to verify the gap problem in MODIS measurements because AOD is measured only in clear sky conditions and these studies show that MODIS AOD has generally excellent agreement with AERONET, as the data used in this work are monthly and not daily averages, the error due to the gap is reduced [52,55-58].

Our study used a monthly AOD at $550 \mathrm{~nm}$ from the MODIS Aqua and Terra Ensemble Level $31 \times 1$ deg product (Collection 6.1) from January 2010 to December 2014 (total of 60 months). The AOD products can be accessed on the GIOVANNI NASA subset ordering web page (https:/ / giovanni.gsfc.nasa.gov/giovanni/, accessed on 1 October 2020). 


\subsection{CAM-Chem Model}

\subsubsection{CAM-Chem Model Introduction}

NCAR Community Atmosphere Model, version 5 (CAM5) with chemistry (CAMChem) was used in this study. CAM5 is the atmospheric component of the Community Earth System Model version 1.2 (CESM-1.2). We conducted our simulations using CAMchem with the MOZART-4 chemical mechanism [59,60], which has demonstrated the ability to represent tropospheric and stratospheric conditions including temperature structure and dynamics [59,61,62]. Offline CAM-chem has been used in the Hemispheric Transport of Air Pollution (HTAP) assessments [63,64]. In [60,65], the authors describe CAM5 in detail. Some physical parameterizations are described here briefly. The deep convection parameterization uses the Zhang-McFarlane scheme [61] and shallow convection [62]. The large-scale microphysics parameterization follows the Morrison-Gettleman double moment scheme [66]. The moist turbulence uses the scheme presented in [62], and radiation parameterization follows the Rapid Radiative Transfer Model (RRTM) [67]. The aerosol model uses the three Modal Aerosol Model (MAM3) [68]; the three modes are accumulation, Aitken and coarse. MAM3 predicts the aerosol mass and the total number in each mode and includes internally mixed components including Black Carbon (BC), primary organic matter (POM), SOA, sea salt, dust and sulfate.

CAM-chem includes the biogenic emission model MEGAN-v2.1 (Model of Emissions of Gases and Aerosols from Nature), through the coupling of the Community Land Model (CLM). This land model performs the online calculation of emissions from vegetation for more than 100 compounds such as isoprene, monoterpenes, oxygenated compounds, sesquiterpenes and nitrogen oxide [69,70]. Fire emissions are adopted from FINN (Fire inventory from NCAR) version 1.5, which is a global database framework for emissions estimated from open burning and serves as an input to atmospheric chemistry and air quality models at both local and global scales. FINN provides daily emission estimates at a horizontal resolution of $\sim 1 \mathrm{~km}^{2}$. It is unique in terms of the availability of products at high temporal and spatial resolution globally and for a large number of chemical species [71,72]. Combining the satellite observations of active fires with emission factors and estimated fuel loading, FINN provides daily high-resolution $(\sim 1 \mathrm{~km})$ open burning biomass estimates for use in global and regional chemical transport models.

Anthropogenic emissions are adopted from the Precursors of Ozone and their Effects in the Troposphere (POET) database for 2000 [59]. Emissions of black and organic carbon resulting from fossil fuel and biofuel combustion for the year 1996 were studied in [73]. The anthropogenic $\mathrm{SO}_{2}$ and $\mathrm{NH}_{3}$ were obtained from the Emission Database for Global Atmospheric Research databases EDGAR-FT2000 and EDGAR-2. The Regional Emission inventory for Asia (REAS) was used for this region, along with the corresponding simulated annual inventory for each year in [74]. While REAS is available for each year, the rest of the emissions were simulated on an annual average basis. Aircraft emissions have global annual totals of $0.63 \mathrm{Tg} \mathrm{yr}^{-1}$ for $\mathrm{NO}, 1.70 \mathrm{Tg} \mathrm{yr}^{-1}$ for $\mathrm{CO}$ and $0.16 \mathrm{Tg} \mathrm{yr}^{-1}$ for $\mathrm{SO}_{2}$. The monthly means for dimethyl sulfide (DMS) were taken from the marine biogeochemistry model HAMOCC5 and were representative of the year 2000 [75]. The GEIAv1 inventory provides $\mathrm{SO}_{2}$ emissions from continuously outgassing volcanoes [76]. Emissions are implemented as a flux boundary condition for the vertical diffusion and are released at the bottom layer except for volcanic factors. CAM-chem is capable of interpolating the emission fields to the model resolution irrespective of the resolution with which they are provided. A simple bilinear interpolation is used, and therefore this does not ensure the exact conservation of emissions between resolutions. Errors are usually small and limited to areas of strong gradients.

Two CAM-chem configurations were used in this work: (i) tropospheric chemistry with MAM3 (hereafter known as CAM-TROPMAM) and (ii) tropospheric-stratospheric chemistry with MAM3 (CAM-STRATMAM). CAM-TROP refers to Trop MOZART chemistry with 103 species, with an extensive tropospheric chemistry scheme including $\mathrm{C}_{2} \mathrm{H}_{2}$, $\mathrm{HCOOH}, \mathrm{HCN}$ and $\mathrm{CH}_{3} \mathrm{CN}$ and reaction rates updated to JPL-2006. The isoprene oxida- 
tion scheme, which is relevant in the troposphere, now includes an increase in glyoxal production and is primarily intended for simulations. Long-term trends in the stratospheric composition are not crucial. Thus, in this configuration, the stratospheric distributions of long-lived species were specified from the earlier Whole Atmosphere Community Climate Model, version 4 (WACCM4.0) simulations. WACCM4 is an extension of the CAM4 $[65,77,78]$. On the other hand, CAM-STRAT refers to Trop-Strat MOZART chemistry and extensive tropospheric and stratospheric chemistry, including the entire stratospheric chemistry from WACCM4 [77].

\subsubsection{CAM-Chem Model Simulation}

Two simulations of global atmospheric composition CAM-TROPMAM and CAMSTRATMAM at a horizontal resolution of $1.9^{\circ}$ (latitude) and $2.5^{\circ}$ (longitude) were performed. The model was integrated for the period 2009-2014. The first-year simulation corresponded to the model's initiation (i.e., 2009), and the subsequent years (2010-2014) were used in the analysis. Vertical levels were divided into 30 unevenly spaced layers, from the surface up to approximately $4.0 \mathrm{hPa}(40 \mathrm{~km})$. The required datasets for setting up the simulations for both configurations are available for download at www.cesm.ucar.edu, (accessed on 9 September 2017). The CAM-chem simulated monthly outputs were interpolated to a horizontal resolution of $1.9^{\circ}$ (latitude) and $2.5^{\circ}$ (longitude). CO and AOD were analyzed on a seasonal basis; i.e., December-January-February (DJF), March-April-May (MAM), June-July-August (JJA), and September-October-November (SON). An additional analysis for August-September-October (ASO) was considered to evaluate the period with the maximum biomass burning, particularly in South America [79].

The output AOD variable of the two model configurations was directly compared with the observed AOD (MODIS). In contrast, the output CO profile was necessary to transform to account for the vertical resolution of the MOPITT retrieval [80] by using the following equation:

$$
F(x)=y_{a}+A\left(H(x)-y_{a}\right)
$$

where $A$ is the kernel of the MOPITT average on the surface, and $H(x)$ is the CO output from the CAM-Chem model on the surface, interpolated onto the MOPITT grid. $y_{a}$ is the a priori concentration of MOPITT on the surface [80]. After the transformation, the modeled $\mathrm{CO}$ at the surface was compared to the surface-level MOPITT CO (Figures 1, 2, 3, 4 and 5b-d). We also performed a direct comparison of surface CO concentrations in both CAM-chem configurations, as shown in Figures S1-S5b-d.

\subsection{Calculating RMSE and Pearson's Correlation Coefficient}

For the model-observation comparisons, we used the NCAR Command Language (NCL). To calculate the root-mean-square error (RMSE) and the Pearson correlation coefficient are used the dim_rmsd_Wrap and escorc functions, respectively. The dim_rmsd_Wrap function computes the temporal root-mean-square-difference at each latitude/longitude grid point, and the escorc function correlates all grid points for each time of the two variables. For more details, see example 3 at https: / / www.ncl.ucar.edu/Document/Functions / Builtin/dim_rmsd.shtml (accessed on 8 June 2018) and example 5 at https://www.ncl.ucar.edu/Document/Functions/Built-in/escorc.shtml (accessed on 8 June 2018).

\section{Results and Discussion}

In this section, we evaluated the CO and AOD variables simulated for 2010-2014 by the CAM-chem model against global satellite-obtained concentrations of surface aerosols (AOD) and CO data to verify the spatial and temporal reproducibility of the model. Two different model configurations, as explained in Section 2, are used. The model results were compared with a priori satellite $\mathrm{CO}$ observations from the Measurements of Pollution in the Troposphere (MOPITT) instrument and AOD from the Moderate-Resolution Imag- 
ing Spectroradiometer (MODIS). Additionally, in Section 3.4, we evaluated FRP and its correlations with $\mathrm{CO}$ and AOD.

\subsection{Seasonal and Spatial Variations of Global CO (Observations and Simulations)}

In this section, we evaluate model simulation against observations, we present the results of the observed CO concentrations (Figure 1a, Figure 2a, Figure 3a, Figure 4a, Figure 5a) and results from experiments with CAM-TROPMAM (Figure 1b, Figure $2 b$, Figure $3 b$, Figure $4 b$, Figure $5 b$ ) and CAM-STRATMAM (Figure 1d, Figure 2d, Figure $3 d$, Figure 4d, Figure 5d) for different seasons (DJF, MAM, JJA, SON) and also for the period with maximum biomass burning over South America (ASO). The gray values in the CO observations are missing values in the satellite data. The model results have no missing value (see the Supplementary Figures S1-S5). Therefore, the results from Equation (4) take into consideration of any missing data. A calculation recommended in the MOPITT manual is performed to compare the CO data from MOPITT against the model. After performing this calculation, shown in Equation (4), the model results present missing values equal to the observed data.

In Figure 1a, the highest CO concentration occurs during DJF, primarily in eastern China, which must be related to urban air pollution. This CO plume also prevails over Southeast Asian countries, such as Bangladesh, Myanmar, Thailand, Laos, Cambodia, Malaysia and western Indonesia, which is associated with biomass burning and can be confirmed in the FRP results. Likewise, the Indian subcontinent shows high CO concentrations during this period, due to biomass burning and urban air pollution, and showed a positive correlation between FRP x CO results and FRP results. This reveals biomass burning processes in southern India and thermoelectric emission, industrial and vehicular emissions in northern India, as suggested in [81]. Higher CO concentrations were also observed in central Africa due to biomass burning in Congo's Equatorial Forest as also shown in the FRP results.

The comparison of the model's results against observations (Figure 1b,d with Figure 1a) shows that both configurations of CAM-chem successfully simulate the spatial distribution characteristics of $\mathrm{CO}$ concentration during DJF, such as a higher concentration over Eastern China, Central Africa, Europe and the United States. Nevertheless, the CAM-TROPMAM configuration slightly overestimates CO concentrations (over Africa, Australia, North America, Southern South America, etc.), while underestimating it over China, Bangladesh and Myanmar (Figure 1c,e). The version of CAM-chem that uses the chemical mechanism in the stratosphere (CAM-STRATMAM) reduce these positive biases, except over India. 

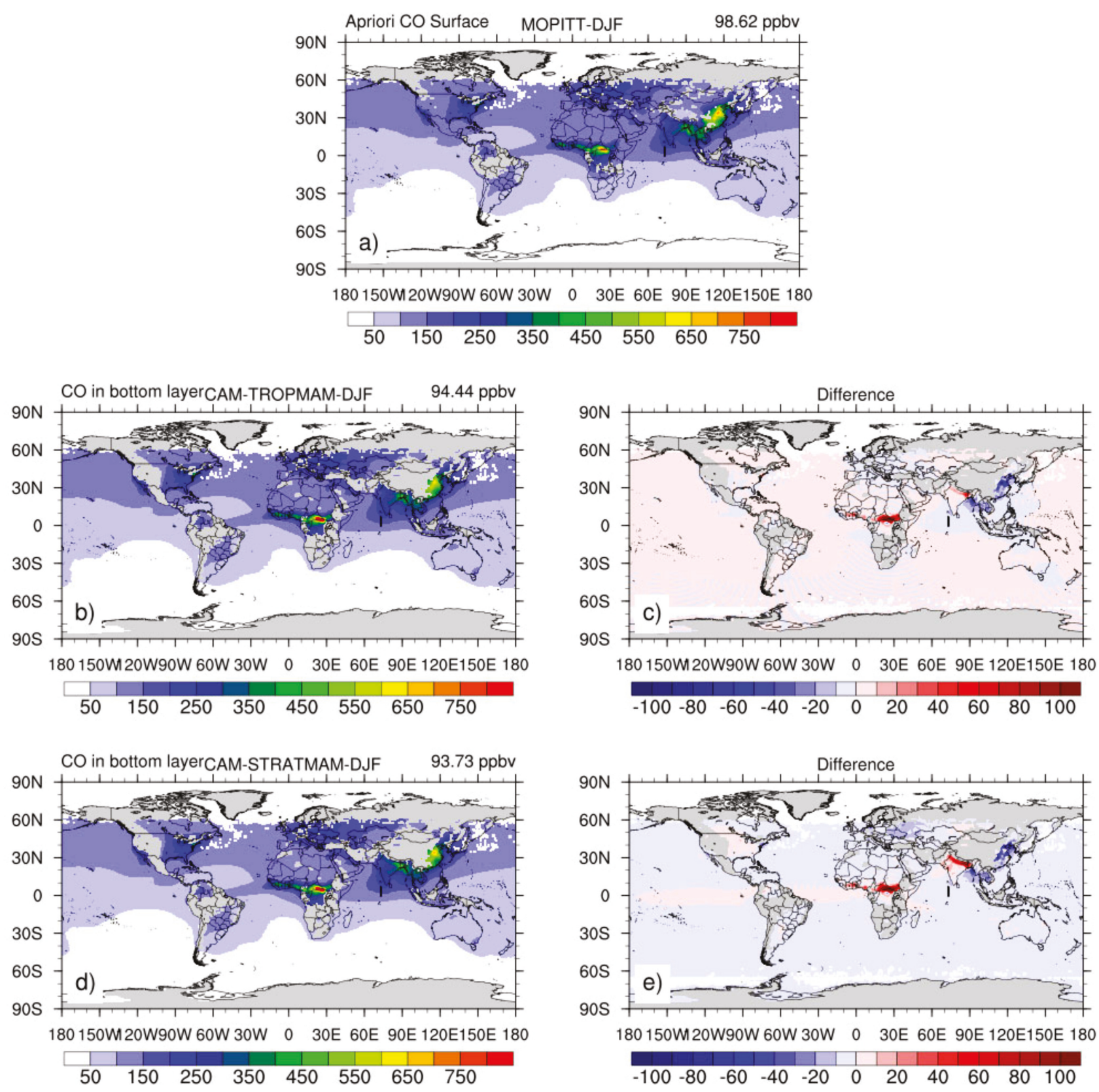

Figure 1. (a) CO (ppb) observed by MOPITT sensor for December-January-February (DJF), in the period of 2010-2014, (b) CO simulated by the CAM5-MAM3 model using tropospheric chemistry and (d) tropospheric/stratospheric chemistry mechanisms using the calculations of Equation (4). The right side of the figure shows the model difference minus the observation (MOPITT), (c) for tropospheric chemistry and (e) for tropospheric/stratospheric chemistry.

During the period of March-April-May (MAM), higher CO concentrations are observed (Figure 2a) in countries south of China, such as Myanmar and Laos and over Europe. In [82], the authors also studied aerosols in China, focusing on the Yangtze River Delta in December 2013 and January 2014. They found that dust aerosols in that region make little difference to cloud properties, and the primary source is anthropogenic activities. Higher CO concentrations were observed over Eastern China than other parts. The highest $\mathrm{CO}$ concentrations occur during MAM in Europe in densely industrialized areas such as the central portion of the continent, including Germany, the Netherlands and Poland and expanding eastward through Ukraine to the western part of Russia, as well as industrialized regions of Italy, France and the British Isles. In Europe, CO concentrations are 
spatially more homogeneous, reflecting the greater urbanization of the continent. Similar to DJF, both configurations of CAM-chem (Figure 2b,d) successfully simulate the spatial distribution characteristics of the CO concentration in MAM. Here, the bias (Figure 2c,e) in both cases is smaller than in DJF; however, the CAM-STRATMAM configuration shows fewer positive biases than the CAM-TROPMAM configuration.
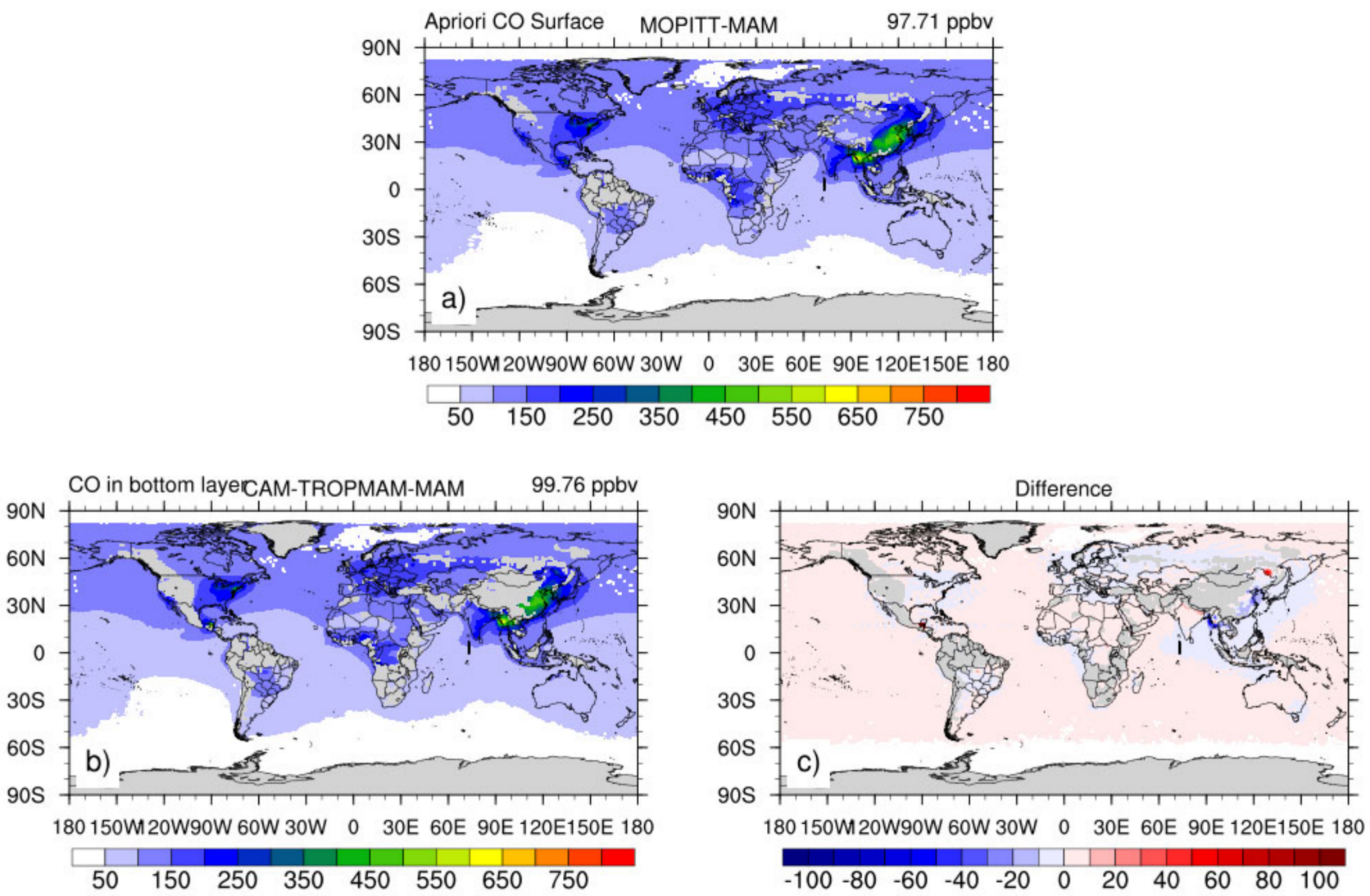

$180150 \mathrm{~W} 20 \mathrm{~W} 90 \mathrm{~W} 60 \mathrm{~W} 30 \mathrm{~W} 0$ 30E 60E 90E 120E150E 180
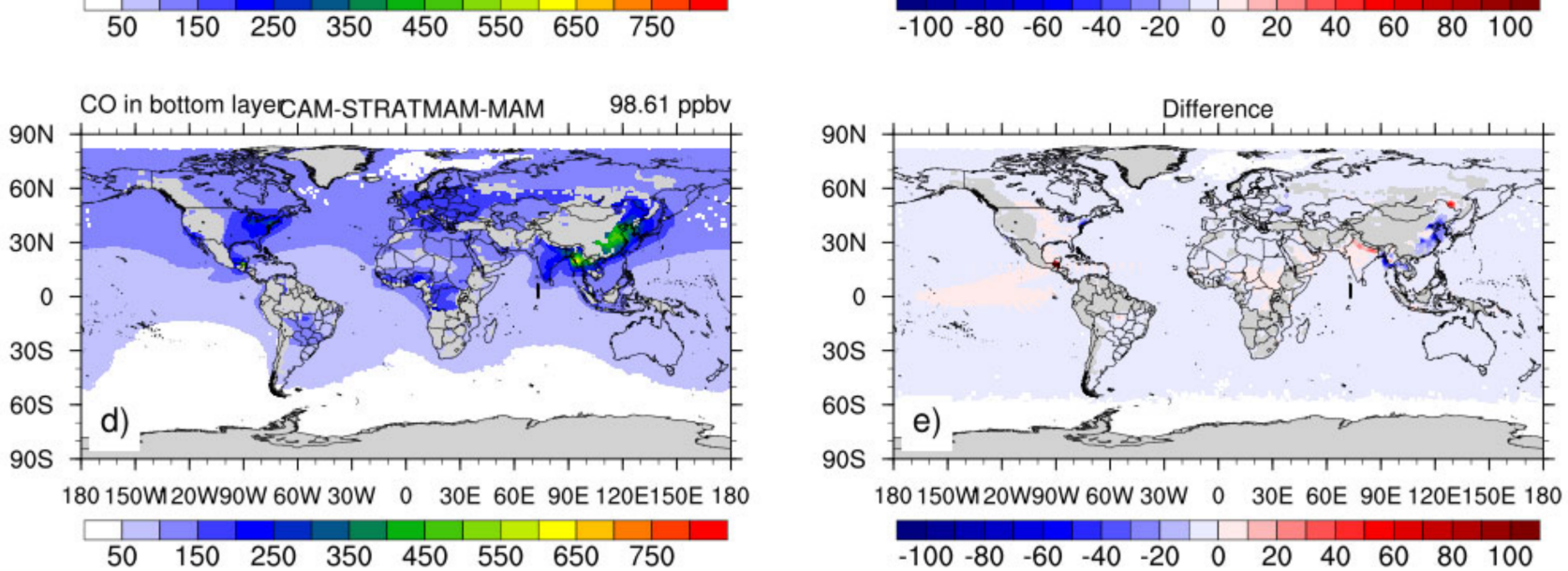

Figure 2. (a) CO (ppb) observed by MOPITT sensor for March-April-May (MAM), in the period of 2010-2014, (b) CO simulated by the CAM5-MAM3 model using tropospheric chemistry and (d) tropospheric/stratospheric chemistry mechanisms using the calculations of Equation (4). The right side of the figure shows the model difference minus the observation (MOPITT), (c) for tropospheric chemistry and (e) for tropospheric/stratospheric chemistry.

In North America, higher concentrations are observed also throughout the Midwestern portion of the US, especially in the densely industrialized northeast and Great Lakes region, where pollution spreads to Southern Canada in the Toronto region. During JJA, the observed CO concentration (Figure 3a) increases in the northeastern US (regions of New 
England and Mid Atlantic of) compared to DJF and MAM. There are higher concentrations also throughout the state of California, near the border with Mexico. In [13], the authors also detected CO emissions from large forest fires in North America using MOPITT, indicating the power of a satellite instrument to assess the surface processes. Figure $3 \mathrm{a}$ also shows that $\mathrm{CO}$ concentrations increase over central South America and western and central Africa (Congo's Equatorial Forest and the transition between forest and savanna in central Africa) in comparison to MAM due to biomass burning. As with the previous seasons (DJF and MAM), both configurations of CAM-chem (Figure 3b,d) perform reasonably in the spatial distribution of $\mathrm{CO}$ concentration during JJA. However, both configurations underestimate levels over the central part of South America (Figure 3c,e). Over Africa and Europe, the CAM-STRATMAM configuration slightly reduces the positive bias shown by the CAM-TROPMAM configuration. In contrast, it increases the negative bias over Eastern China.
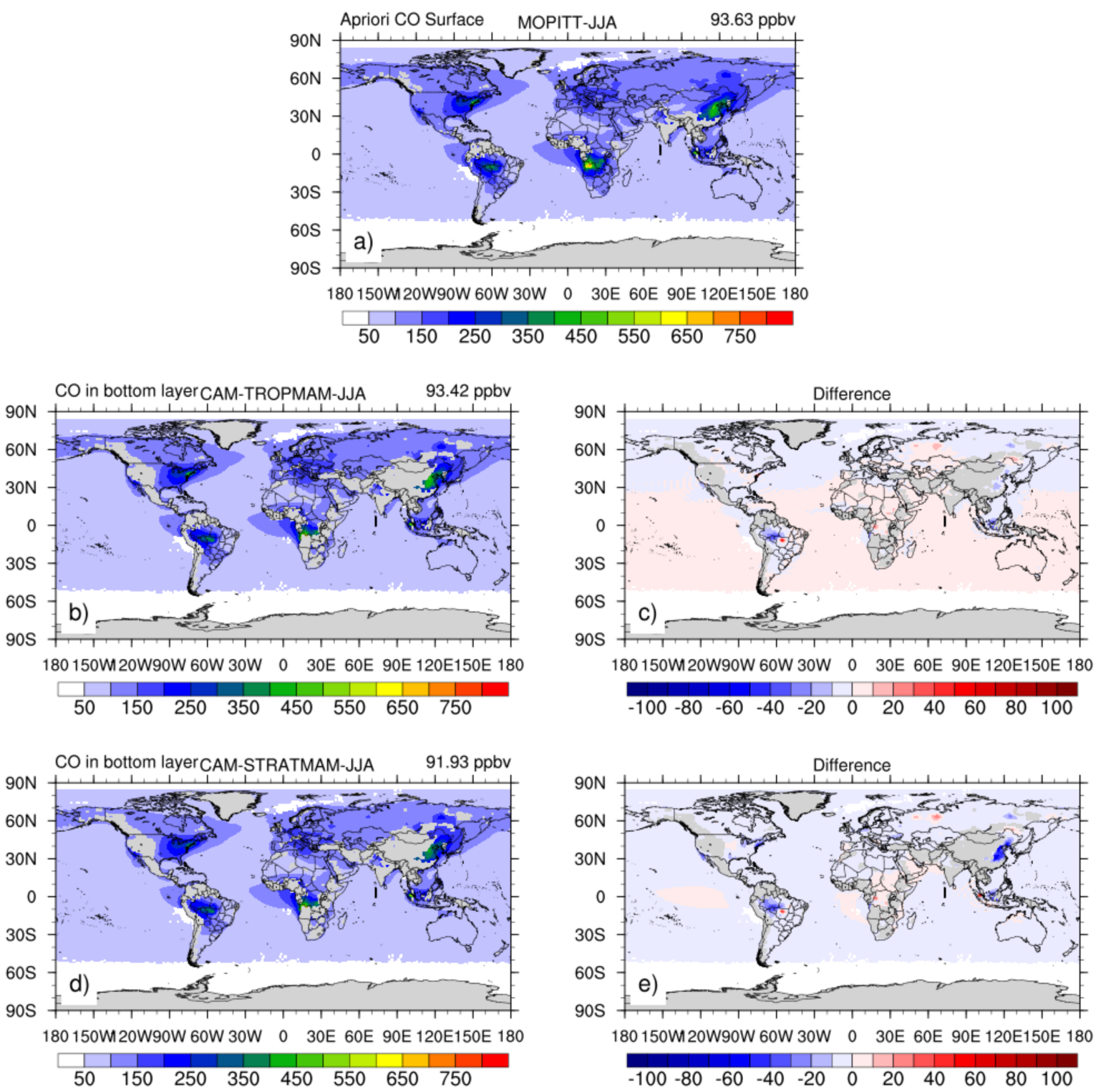

Figure 3. (a) CO (ppb) observed by MOPITT sensor for June-July-August (JJA), in the period of 2010-2014, (b) CO simulated by the CAM5-MAM3 model using tropospheric chemistry and (d) tropospheric/stratospheric chemistry mechanisms using the calculations of Equation (4). The right side of the figure shows the model difference minus the observation (MOPITT), (c) for tropospheric chemistry and (e) for tropospheric/stratospheric chemistry. 
During SON, the observed CO concentrations (Figure 4a) have increased in the Southern Hemisphere compared to the previous season, including central Africa and northern Australia; and in the Northern Hemisphere, over the south Asian countries. CO concentrations are highest over the Southern Hemisphere during ASO (Figure 5a). In South America, the highest $\mathrm{CO}$ concentrations were observed over Brazil, in the west and central portions of the country (in Mato Grosso, Pará, Rondônia, Acre and Amazonas), and on the Brazilian border with Bolivia. The main reason for this is agriculture in regions close to the Amazon Forest and the expansion of the agricultural frontier in this region. These months correspond to the dry season, favoring the accumulation of pollutants in the troposphere. The analysis also shows that $\mathrm{CO}$ concentrations started to increase during JJA (Figure 3a) over central Africa, US, central South America and other parts of the Southern Hemisphere and reached their peak in the Southern Hemisphere during ASO (Figure 5a). Similar to the model results in JJA, the CAM-chem model performs well regarding the spatial distribution of the CO concentration in SON (Figure $4 b, d$ ) and ASO (Figure 5b,d). Over Africa and India, the CAM_STRATMAM configuration slightly reduces the positive bias shown by the CAM-TROPMAM configuration (Figure 4c,e). However, similar to JJA, it increases the negative bias over Eastern China.
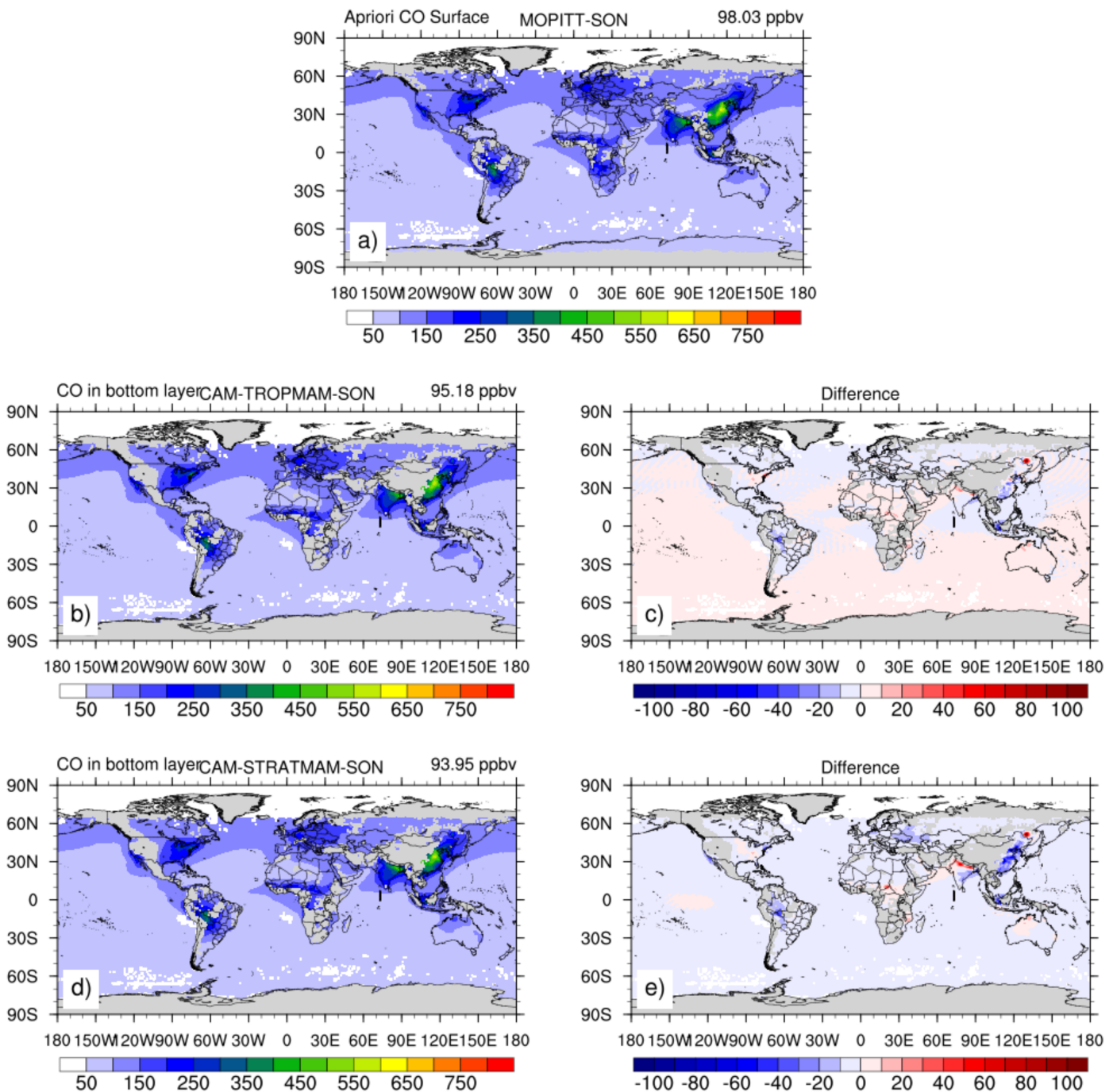

Figure 4. (a) CO (ppb) observed by MOPITT sensor for September-October-November (SON), in the period of 2010-2014, (b) CO simulated by the CAM5-MAM3 model using tropospheric chemistry and (d) tropospheric/stratospheric chemistry mechanisms using the calculations of Equation (4). The right side of the figure shows the model difference minus the observation (MOPITT), (c) for tropospheric chemistry and (e) for tropospheric/stratospheric chemistry. 

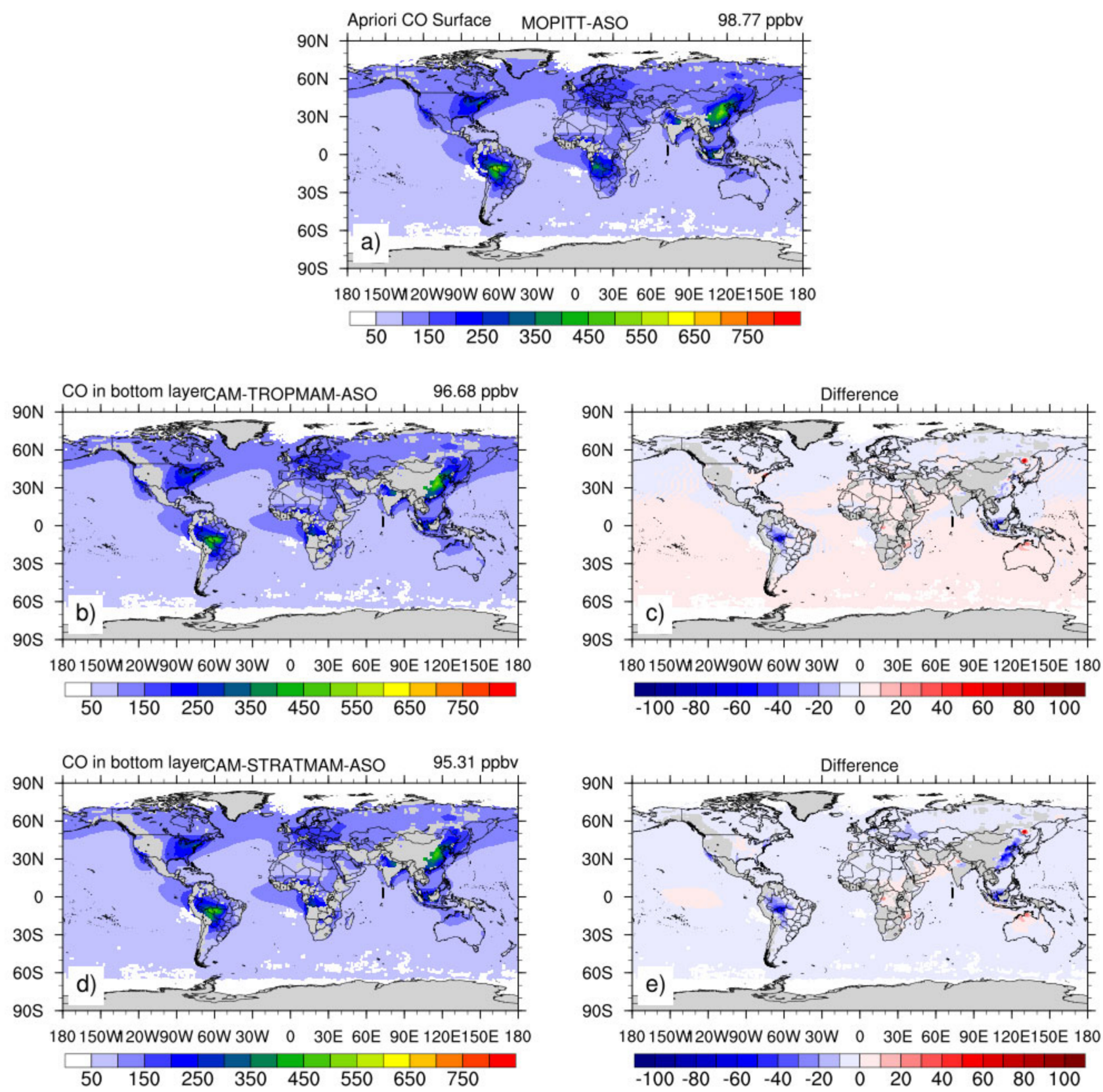

Figure 5. (a) CO (ppb) observed by MOPITT sensor for August-September-October (ASO), in the period of 2010-2014, (b) CO simulated by the CAM5-MAM3 model using tropospheric chemistry and (d) tropospheric/stratospheric chemistry mechanisms using the calculations of Equation (4). The right side of the figure shows the model difference minus the observation (MOPITT), (c) for tropospheric chemistry and (e) for tropospheric/stratospheric chemistry.

In summary, in this section, both configurations of CAM-chem (CAM-TROPMAM and CAM-STRATMAM) simulate reasonably well the spatial distribution characteristics of the $\mathrm{CO}$ concentration during all seasons (DJF, MAM, JJA, SON and ASO). In the CO simulations with the version of CAM-chem that uses the chemical mechanism in the stratosphere (contrary to the tropospheric-only version, CAM-TROPMAM), impacts occur mainly in the tropical and temperate regions of the globe; i.e., up to \pm 40 degrees. Over these regions, while the tropospheric version overestimates the $\mathrm{CO}$ concentrations, mainly over Africa, and equatorial regions (especially over the Atlantic and western Pacific Oceans), the inclusion of stratospheric chemistry results in a decrease in the positive bias. 
The decrease in the positive bias and the intensification of the negative bias (e.g., over China) in the CAM-STRATMAM configuration is probably related to the higher $\mathrm{CO}$ consumption. This configuration contains 28 photolysis reactions more than CAMTROPMAM. There is an underestimation in CO emission inventories in China due to a severe underestimation of residential coal combustion for heating and potentially for cooking $[83,84]$ and underestimation of Northern Hemisphere $(\mathrm{NH})$ extratropical CO found in global models $[85,86]$ there are other confounding factors. Reference [87] found large inter-model variability in the regional distribution of $\mathrm{OH}$ and an overestimation of $\mathrm{OH}$ in the Northern Hemisphere.

Reference [88] examined in detail a one-year global reanalysis of $\mathrm{CO}$ based on the assimilation of conventional meteorological observations and MOPITT multispectral CO retrievals in CESM. Their results showed that the total tropospheric estimate CO burden in 2002 is around $371 \mathrm{Tg}$ for MOPITT Reanalysis and $291 \mathrm{Tg}$ for the Control run, suggesting that direct emissions of $\mathrm{CO}$ and hydrocarbons are too low in the inventory used, and chemical oxidation, transport, and deposition processes are not accurately represented in the model. Increases in $\mathrm{CO}$ led to the net reduction of $\mathrm{OH}$ and subsequent longer lifetime of $\mathrm{CH}_{4}$ (Control Run: 8.7 years versus MOPITT Reanalysis: 9.3 years). CAM-chem modeling helps explain the source contributions and highlights the importance of fire, the missing variability in the empirical model could be due to anthropogenic sources [89].

Furthermore, the amounts of $\mathrm{CO}$ in the two model configurations are different, as shown in Table 1. The emission, burden, dry deposition, loss by chemical reaction, and CO lifetime are also presented annually.

Table 1. Global balance of CO in the two configurations of the model: tropospheric chemistry only (CAM-TROPMAM) and tropospheric and stratospheric chemistry (CAM-STRATMAM).

\begin{tabular}{ccc}
\hline & CAM-TROPMAM & CAM-STRATMAM \\
\hline CO burden (Tg) & 341.919 & 280.386 \\
CO emissions (Tg/year) & 1116.925 & 1116.925 \\
CO dry deposition (Tg/year) & - & 118.412 \\
CO loss by chemical reaction (Tg/year) & 1464.426 & 1522.102 \\
CO lifetime (years) & 0.233 & 0.171 \\
\hline
\end{tabular}

Using stratospheric chemistry (STRATMAM), there is a dry deposition effect for CO which is not present in the configuration with tropospheric chemistry only (TROPMAM). $\mathrm{CO}$ loss due to chemical reactions is greater in STRATAM than in TROPMAM, and the CO lifetime is shorter in the STRATMAM configuration than in TROPMAM. This explains the decrease in positive bias in the STRATMAM configuration and the intensification of the negative bias in the same configuration.

\subsection{Seasonal and Spatial Variations of Global AOD (Observations and Simulations)}

During DJF, high AOD concentrations are observed (Figure 6a) over central and northern Africa, central and south Asia due to dust emission and eastern China due to urban pollution, increasing substantially during MAM (Figure 7a), intensifying the concentration of dust in these regions, as can be seen in [90] and increasing the concentration of pollutants from urban emissions in eastern China. During the MAM period, higher AOD values are observed over Vietnam, Laos, Bangladesh, Pakistan, Iraq and Kuwait, and North Africa. The increasing AOD over North Africa is due to dust and higher AOD values in Southeast Asia is due to the burning of biomass, as shown in Figure 13 in DJF and MAM. In [91], following the pattern shown in Figure 7a, the authors identified a positive AOD pattern over large parts of the Middle East during 2001-2012 when linking the annual AOD to precipitation, soil moisture and surface winds to identify regions in which these attributes are directly related to AOD in Saudi Arabia, Iraq and Iran. With regard to the surface wind speed, the coastal area of the Red Sea in Africa is relevant to Saudi Arabia's AOD. Using multiple linear regression, the authors showed that AOD 
patterns and interannual variability can be attributed to soil moisture, precipitation and surface winds, as the main factors that control the dust cycle in this region. The positive trend of AOD is related to a negative trend of soil moisture. Since lower soil moisture translates to increased dust emissions, anthropogenic aerosols and aerosol precursors alone not necessarily explain these observations. Instead, this study suggests that the increase in temperature and the decrease in relative humidity in the last decade have promoted soil drying, leading to increased emissions of dust and AOD; consequently, an increase in AOD is expected due to climate change [92].

The comparison of the model results for DJF (Figure 6b,d) and MAM (Figure 7b,d) with the observations (Figures 6a and 7a) shows that both configurations of CAM-chem simulate the spatial distribution characteristics of AOD substantially reasonable. Nevertheless, both configurations overestimate AOD levels for central Africa and underestimate them over China. Over Africa, CAM-STRATMAM overestimates AOD levels even more than CAM-TROPMAM.
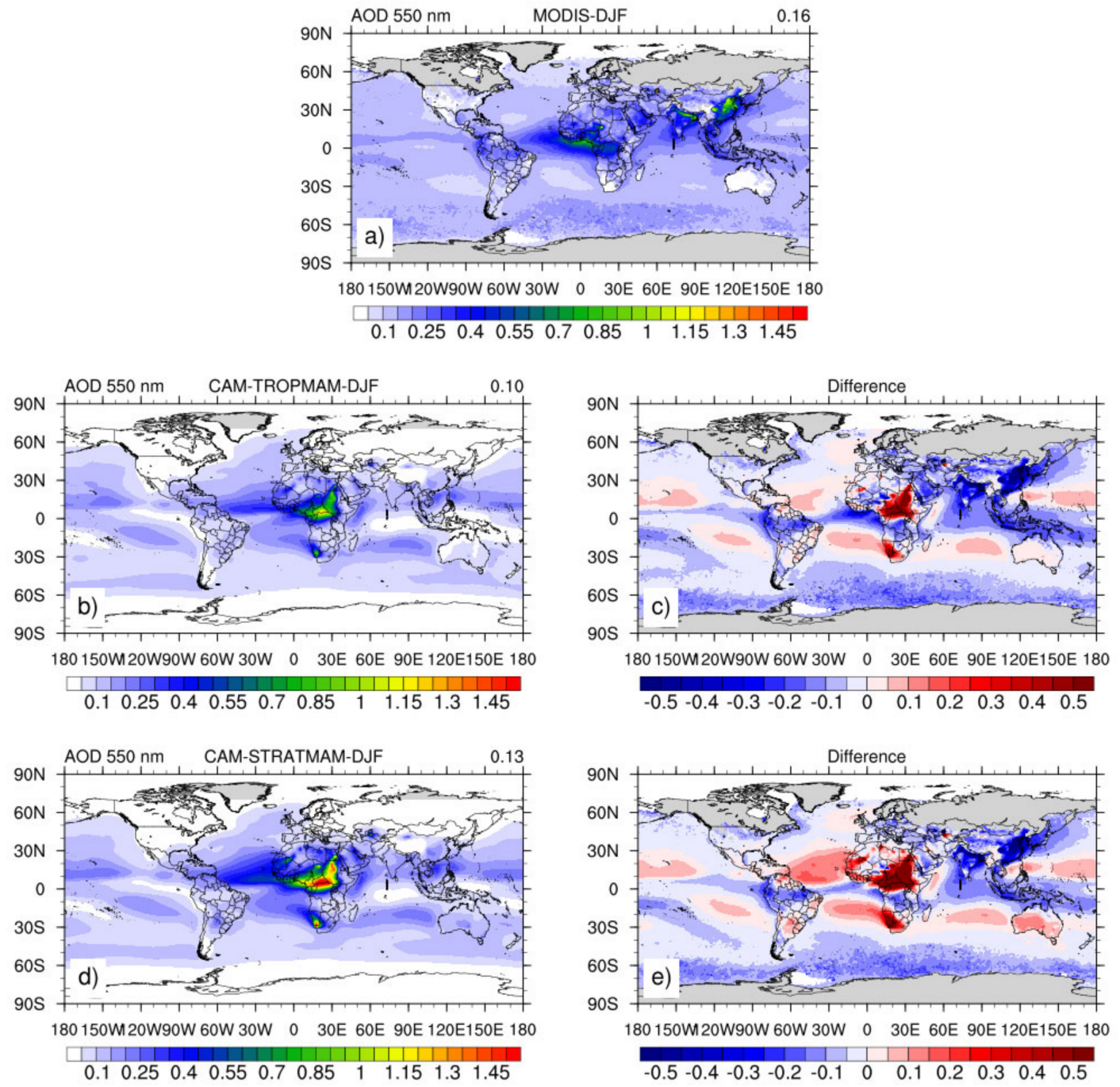

Figure 6. (a) AOD observed by MODIS sensor for December-January-February (DJF), in the period of 2010-2014, (b) AOD simulated by the CAM5-MAM3 model using tropospheric chemistry and (d) tropospheric/stratospheric chemistry mechanisms. The right side of the figure shows the model difference minus the observation (MODIS), (c) for tropospheric chemistry and (e) for tropospheric/stratospheric chemistry. 


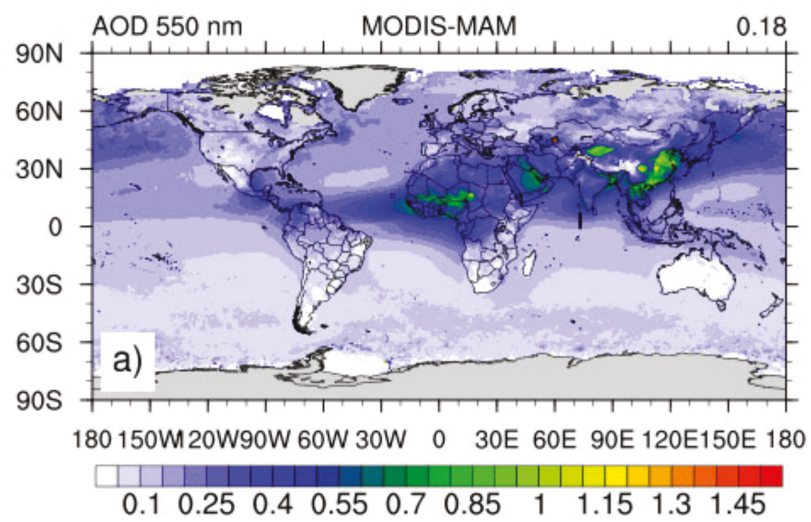

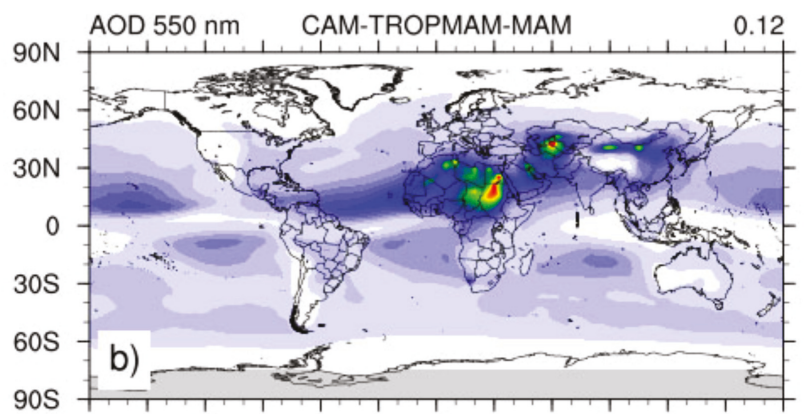

180150W20W90W 60W 30W O 30E 60E 90E 120E150E 180

$\begin{array}{lllllllllll}0.1 & 0.25 & 0.4 & 0.55 & 0.7 & 0.85 & 1 & 1.15 & 1.3 & 1.45\end{array}$

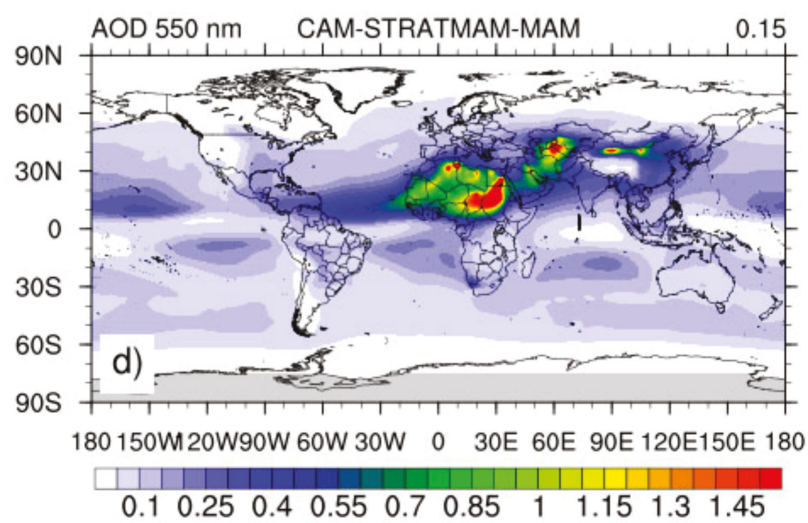

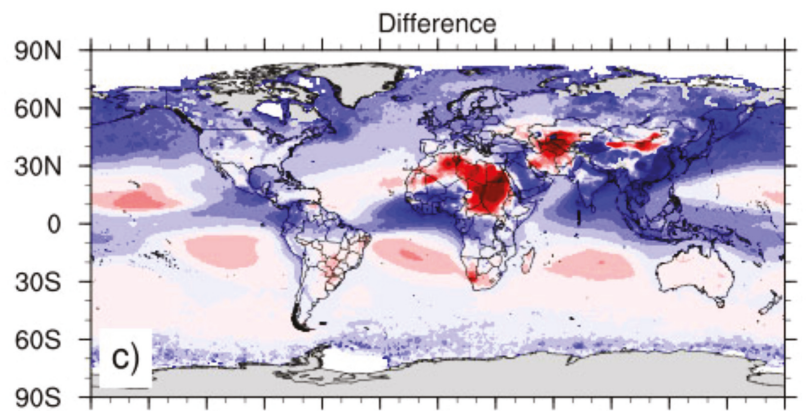

$180150 \mathrm{~W} 20 \mathrm{~W} 90 \mathrm{~W} 60 \mathrm{~W} 30 \mathrm{~W} 0 \quad 30 \mathrm{E}$ 60E 90E 120E150E 180

$\begin{array}{lllllllllll}-0.5 & -0.4 & -0.3 & -0.2 & -0.1 & 0 & 0.1 & 0.2 & 0.3 & 0.4 & 0.5\end{array}$

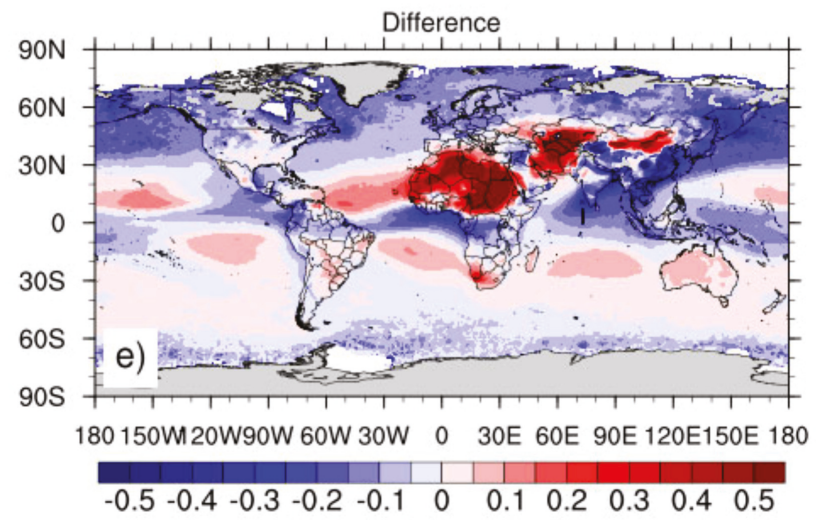

Figure 7. (a) AOD observed by MODIS sensor for March-April-May (MAM), in the period of 2010-2014, (b) AOD simulated by the CAM5-MAM3 model using tropospheric chemistry and (d) tropospheric/stratospheric chemistry mechanisms. The right side of the figure shows the model difference minus the observation (MODIS), (c) for tropospheric chemistry and (e) for tropospheric/stratospheric chemistry.

During JJA (Figure 8a), the highest AOD average occurs because of the increased aerosol concentration in central Asia, the Sahara region in Africa, central South America, India, Pakistan, Iran, Oman, Yemen, Saudi Arabia and Syria. This can be related to the resuspension of particulate matter in the form of dust associated with transboundary pollutants from several desert terrains which influence regions such as the Arabian desert. The dominance of coarse dust particles in desert regions of Saudi Arabia and the transport of dust aerosol from the Arabian Peninsula towards western India and Pakistan have been discussed in detail in [91,92]. During JJA, there is a peak in aerosol concentrations in the Northern Hemisphere when compared to the other seasons of the year. 
JJA is recognized as a peak AOD season over the Chinese and Arabian desert regions [92]. High AOD values are also found in northern and western Africa due to the Sahara desert and in Congo and Gabon, probably due to biomass burning (c.f., [93]). The model results for JJA (Figure 8b,d) show that both configurations of CAM-chem overestimate AOD levels over Africa, Saudi Arabia and South America but underestimate them over India and China. Over South America and Africa, CAM-STRATMAM overestimates AOD levels much more than CAM-TROPMAM.
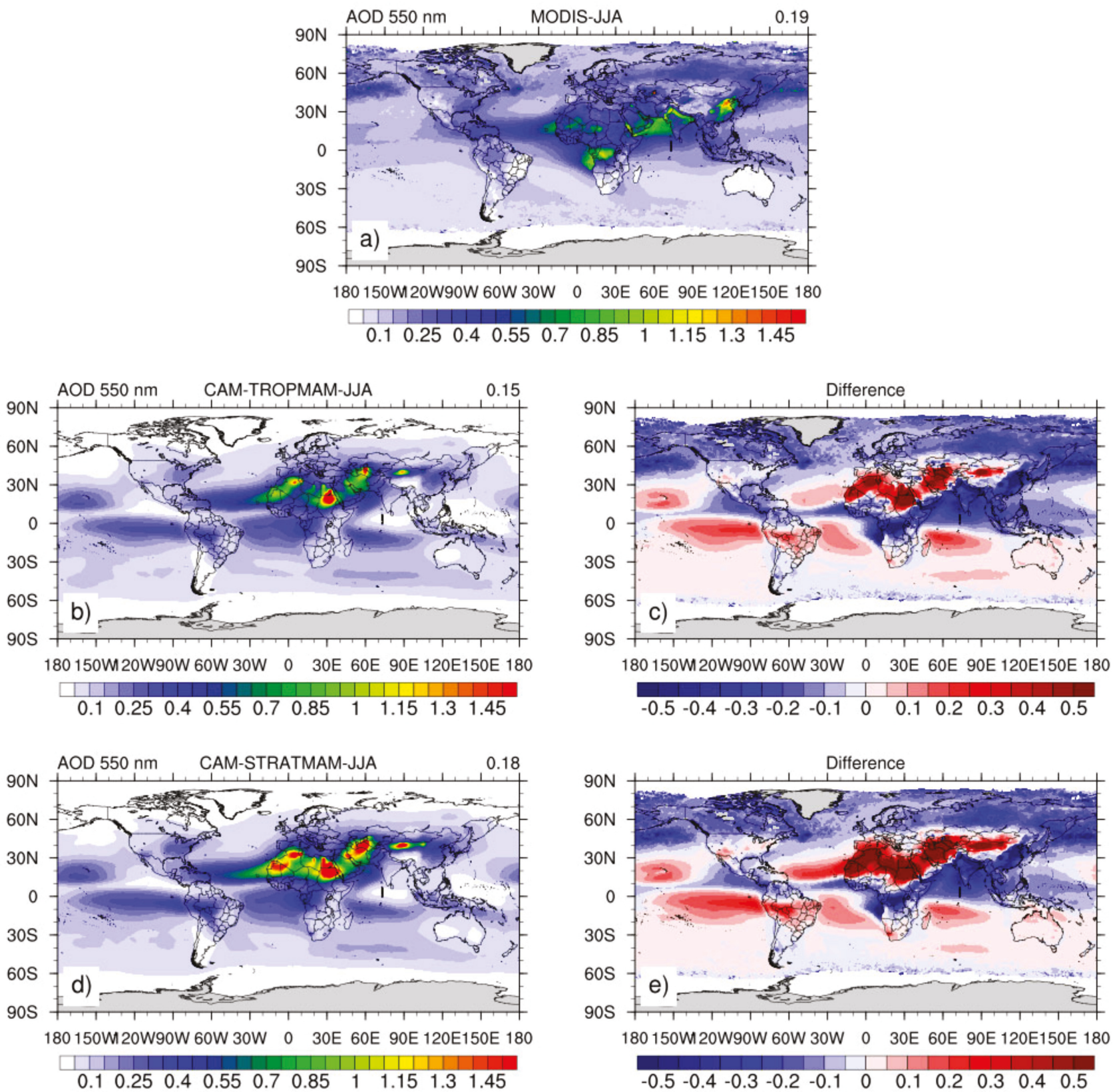

Figure 8. (a) AOD observed by MODIS sensor for June-July-August (JJA), in the period of 2010-2014, (b) AOD simulated by the CAM5-MAM3 model using tropospheric chemistry and (d) tropospheric/stratospheric chemistry mechanisms. The right side of the figure shows the model difference minus the observation (MODIS), (c) for tropospheric chemistry and (e) for tropospheric/stratospheric chemistry.

Higher values of AOD are observed during SON and ASO (see Figures 9a and 10a) in the Southern Hemisphere, as well as the highest concentration of $\mathrm{CO}$ as described above, in the Brazilian states of Mato Grosso, Rondônia, Amazonas and Pará and the Brazilian border 
of the states of Mato Grosso and Rondônia with Bolivia and Paraguay, which occurs due to biomass burning in the dry period in the region (c.f., [94,95]). The distribution of AOD over the globe for the period of July 2002 to December 2009 was analyzed in [96], using the seasonal climatology of MODIS Aqua AOD combined with the Deep Blue algorithm's measured AOD at $550 \mathrm{~nm}$. In [96], the authors found a global distribution of AOD similar to our study, with global averages that were only $7.1 \%$ and 5.9\% higher during DJF and MAM and 5.9\% and 7.7\% lower during JJA and SON, respectively, when compared to this study.

In SON and ASO seasons, the decreased pollutant content (AOD) over India, Pakistan, China and other South Asian countries may be due to the washout of pollutants from the atmosphere as a result of precipitation. A detailed discussion on the removal of pollutants from the atmosphere due to precipitation can be found in [97]. The rainfall washout process limits the aerosol prevalence over the Chinese and Arabian desert region as reported in [92]. Using 12 years of in situ and satellite observations, in [98], the authors found positive correlations between aerosol loading and cloud properties as well as rainfall over the Indian summer monsoon region. In [98], the authors reported that desert dust aerosol levels over the Arabian Sea, west Asia and the Arabian Peninsula are significantly correlated with the intensity of the Indian summer monsoon. Due to the heating of the atmosphere, dust aerosols induce large-scale convergence over North Africa and the Arabian Peninsula, increasing the flow of moisture over India.

The model results for SON (Figure 9b,d) and ASO (Figure 10b,d) compared with observations (Figures 9a and 10a) show that both configurations of CAM-chem overestimate levels over northeastern Africa and underestimate them over southern Africa, eastern China and northern India. CAM-STRATMAM overestimates the levels much more than CAMTROPMAM over Africa. However, the model performs better over South America during SON and ASO. Furthermore, the amounts of the species of aerosols in the two model configurations are different, as shown in Table 2. The emission burden of the species of aerosols are also presented annually.
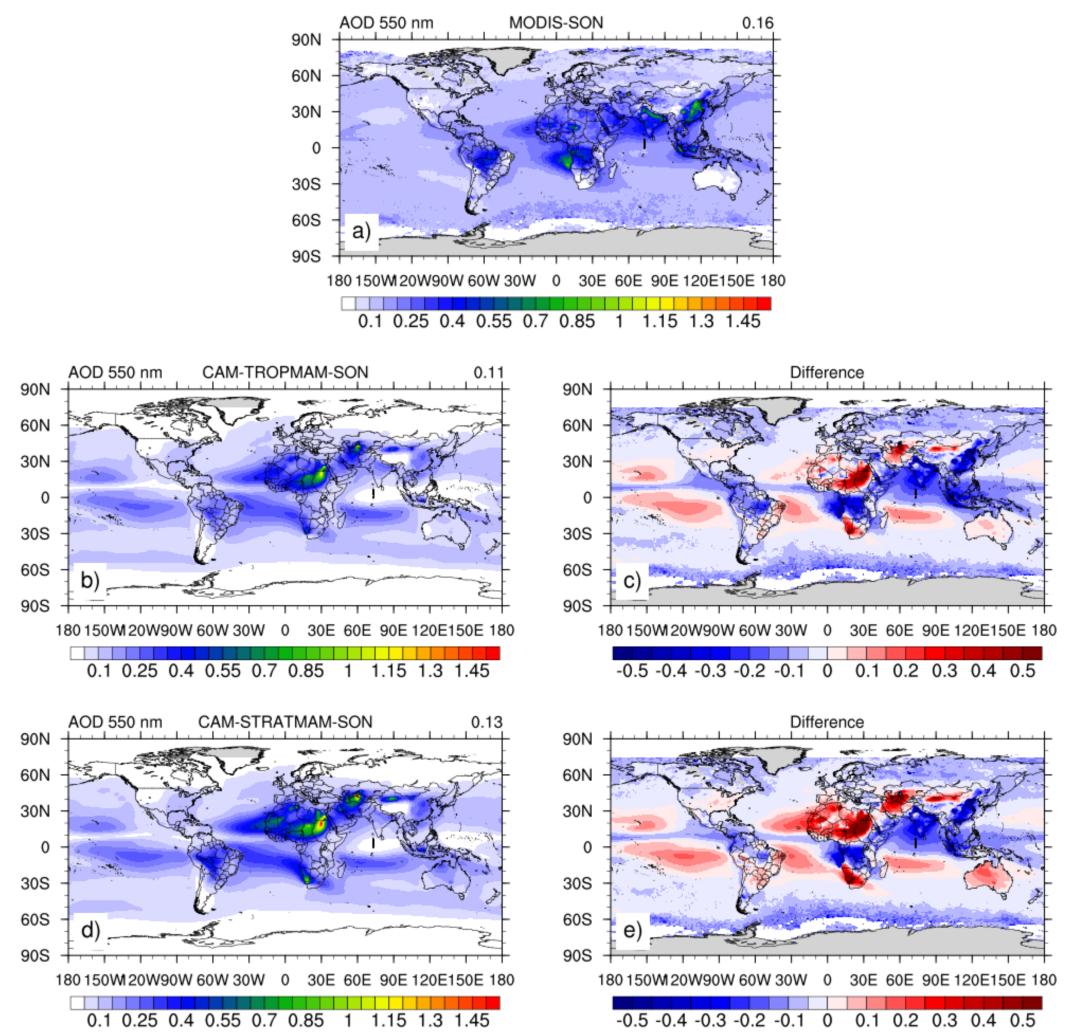

Figure 9. (a) AOD observed by MODIS sensor for September-October-November (SON), 
in the period of 2010-2014, (b) AOD simulated by the CAM5-MAM3 model using tropospheric chemistry and (d) tropospheric/stratospheric chemistry mechanisms. The right side of the figure shows the model difference minus the observation (MODIS), (c) for tropospheric chemistry and (e) for tropospheric/stratospheric chemistry.
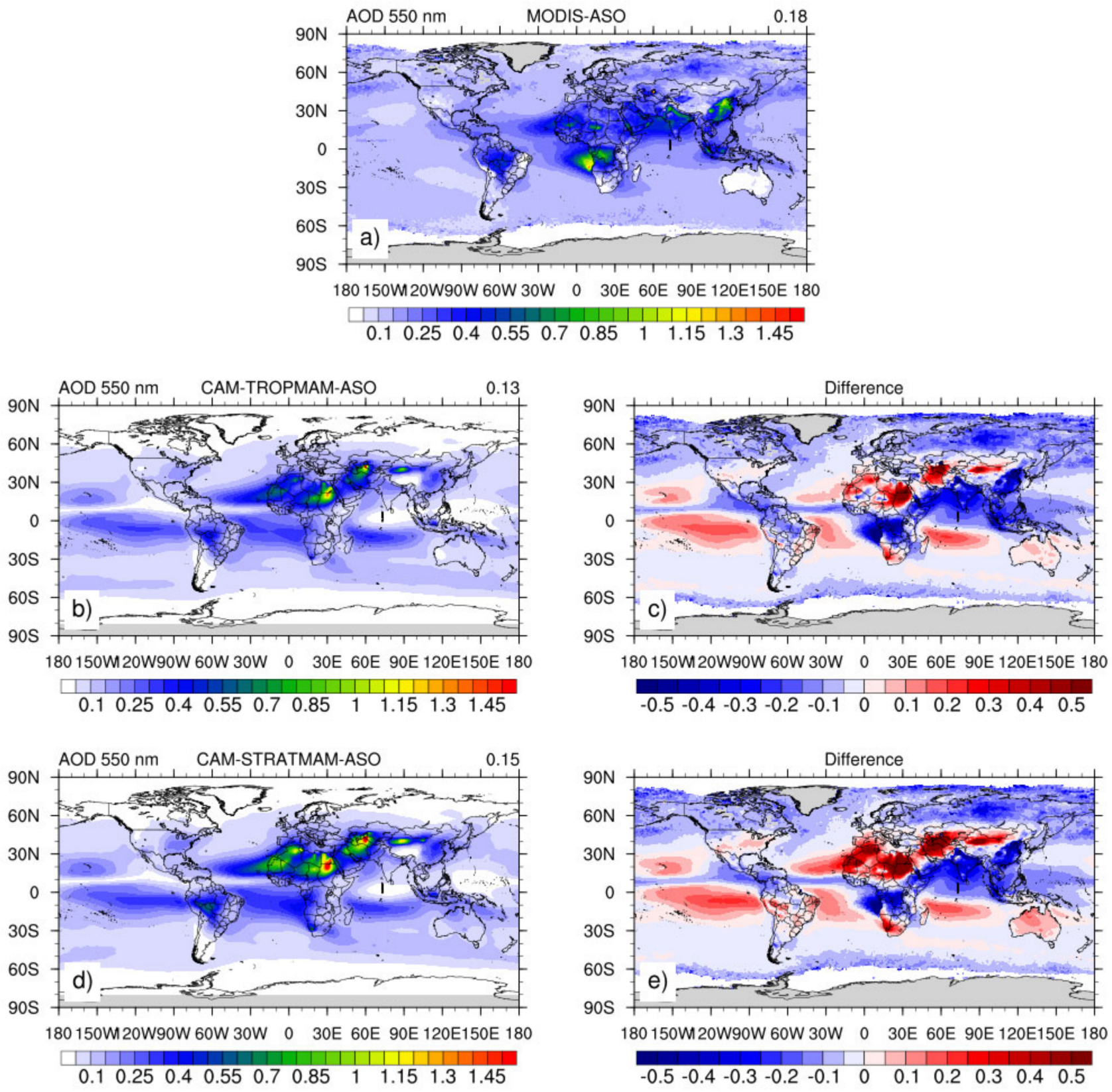

Figure 10. (a) AOD observed by MODIS sensor for August-September-October (ASO), in the period of 2010-2014, (b) AOD simulated by the CAM5-MAM3 model using tropospheric chemistry and (d) tropospheric/stratospheric chemistry mechanisms. The right side of the figure shows the model difference minus the observation (MODIS), (c) for tropospheric chemistry and (e) for tropospheric/stratospheric chemistry. 
Table 2. Global burden of aerosols in the two configurations of the model: tropospheric chemistry only (CAM-TROPMAM) and tropospheric and stratospheric chemistry (CAM-STRATMAM).

\begin{tabular}{lcc}
\hline & CAM-TROPMAM & CAM-STRATMAM \\
\hline Black carbon aerosol burden $\left(\mathrm{g} / \mathrm{m}^{2}\right.$ year) & 18.44 & 18.67 \\
Dust aerosol burden $\left(\mathrm{g} / \mathrm{m}^{2}\right.$ year) & 6130.85 & 9382.13 \\
Particulate organic matter burden $\left(\mathrm{g} / \mathrm{m}^{2}\right.$ year) & 131.76 & 133.05 \\
Sea salt aerosol burden $\left(\mathrm{g} / \mathrm{m}^{2}\right.$ year) & 2438.23 & 2425.96 \\
Sulfate aerosol burden $\left(\mathrm{g} / \mathrm{m}^{2}\right.$ year) & 361.53 & 366.75 \\
Secondary organic aerosol burden $\left(\mathrm{g} / \mathrm{m}^{2}\right.$ year) & 234.62 & 371.45 \\
\hline
\end{tabular}

In summary, the model has difficulty capturing the exact location of the maxima of the seasonal AOD distributions in both configurations. In both configurations, AOD levels were overestimated over the desert regions of Africa and the Middle East in all seasons but significantly underestimated over eastern China and northern India. CAM-STRATMAM overestimates the AOD much more than CAM-TROPMAM over Africa and the Middle East, as seen in the amount of dust aerosol in CAM-STRATMAM is 35\% than in CAMTROPMAM. Similar results were found in the works of $[60,65,78,99,100]$ where comparison of the CAM-chem model with observed data from MODIS show an overestimated bias over North Africa and Central Asia desert regions. The highest dust aerosol emission in the model is probably higher than in reality [66]. These works also show underestimations over Central and North America, Europe, Russia, and East China, similar to those found in the current work. In [78], authors report that the underestimated AOD in these regions may be related to underestimating black carbon emissions in the model. Finally, CAM-chem (in both experiments) successfully simulates the spatial distribution characteristics of AOD over South America during the period with the maximum biomass burning in ASO.

\subsection{Modeled Results vs. Observation: Correlation and RMSE}

Figure 11a,b (Figure 11c,d) show the comparison of the annual correlation between observed and simulated global AOD (CO) in both model configurations: using tropospheric chemistry and tropospheric/stratospheric chemistry mechanisms. Both simulations present very similar results (Figure 11a,b and Figure 12a,b). The CAM-chem model simulation with reactions in the stratosphere yields a positive amplified bias for North and West Africa. The AOD tends to be underestimated in both the versions for latitudes above $30^{\circ} \mathrm{N}$, as shown in Figures 6-10, except for some regions; i.e., Iran, Turkmenistan, Uzbekistan (Turkestan Desert), Taklamakan and the Gobi Desert. The annual cycle is analyzed in terms of the correlation coefficient calculated from the monthly average data set, and the model simulations indicate that the biomass burning is still a persisting problem, producing AOD due to anthropogenic activities and wildfires. Correlation coefficients range from 0.4 to 0.8 , which shows a reasonable representation of AOD variations. The RMSE values in Figure 12a,b show good agreement between the measurements of AOD from the satellite and model-predicted values for both configurations. 

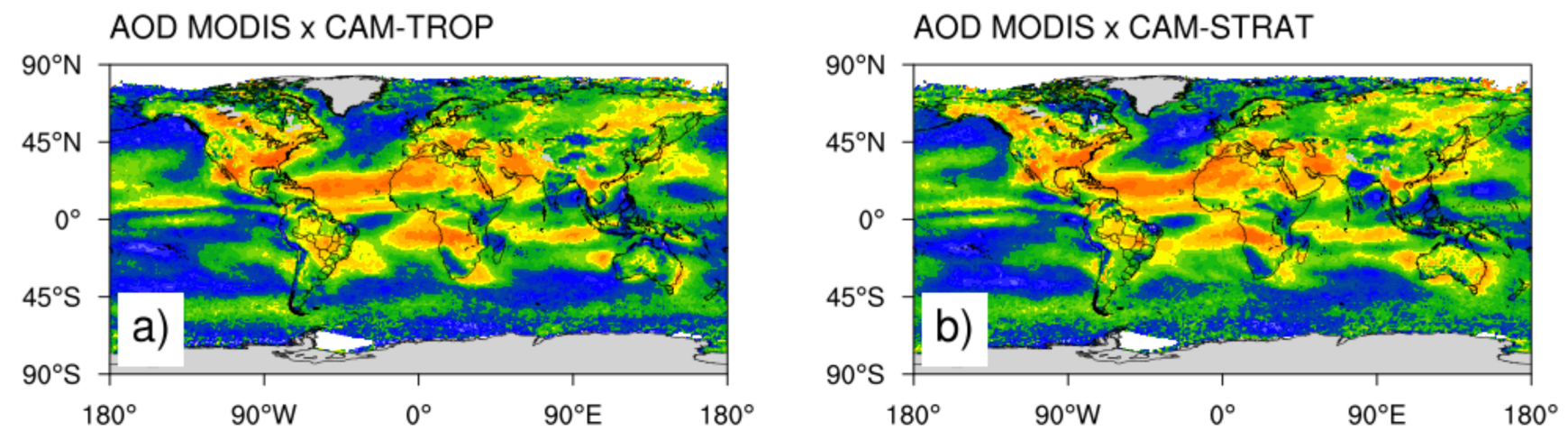

\section{CO MOPITT $\times$ CAM-TROP}
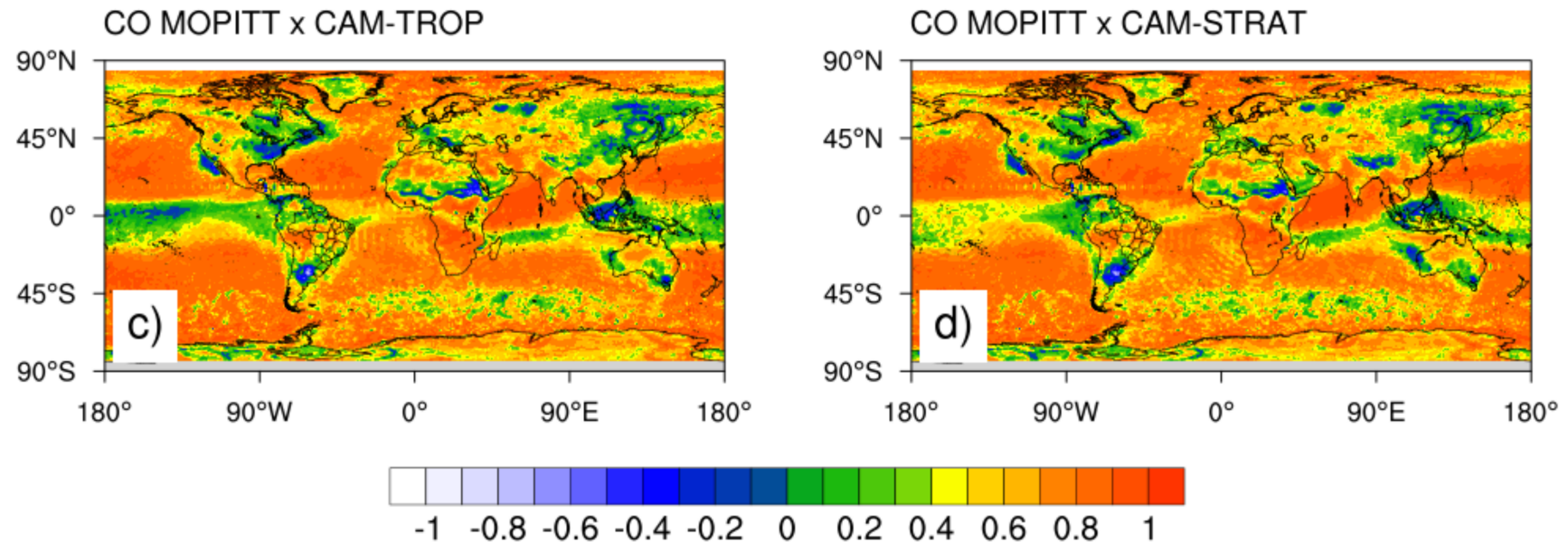

Figure 11. Correlation maps between the annual average of observed and simulated AOD (a,b) and CO (ppb) (c,d) in both model configurations.

Figure 12a,b show the RMSE maps between annual averages of observed and simulated AOD. The root mean square error (RMSE) is commonly used to assess the quality of the fit of a model. It is the root of the mean square error of the difference between the modeled value and the observed value. Unlike the bias and the correlation coefficient presented in this article, the RMSE has a unit (dimension) similar to the dimension of the observed and simulated values. The zero value of RMSE indicates a perfect forecast, and this value increases as the difference between the model and observation increases. Figure 12a (tropospheric chemistry) andFigure 12b (tropospheric and stratospheric chemistry) show lower RMSE values for almost every part of the globe. However, higher values of RMSE were obtained in South and Northeast Africa, Kazakhstan and Uzbekistan for the version that includes reactions in the stratosphere. It also shows higher RMSE values in the extreme north of India and eastern China, but there is no amplification of the values when stratospheric chemistry is included. In Figures 6-10, a greater bias difference is shown for the observed and modeled data for these regions. 

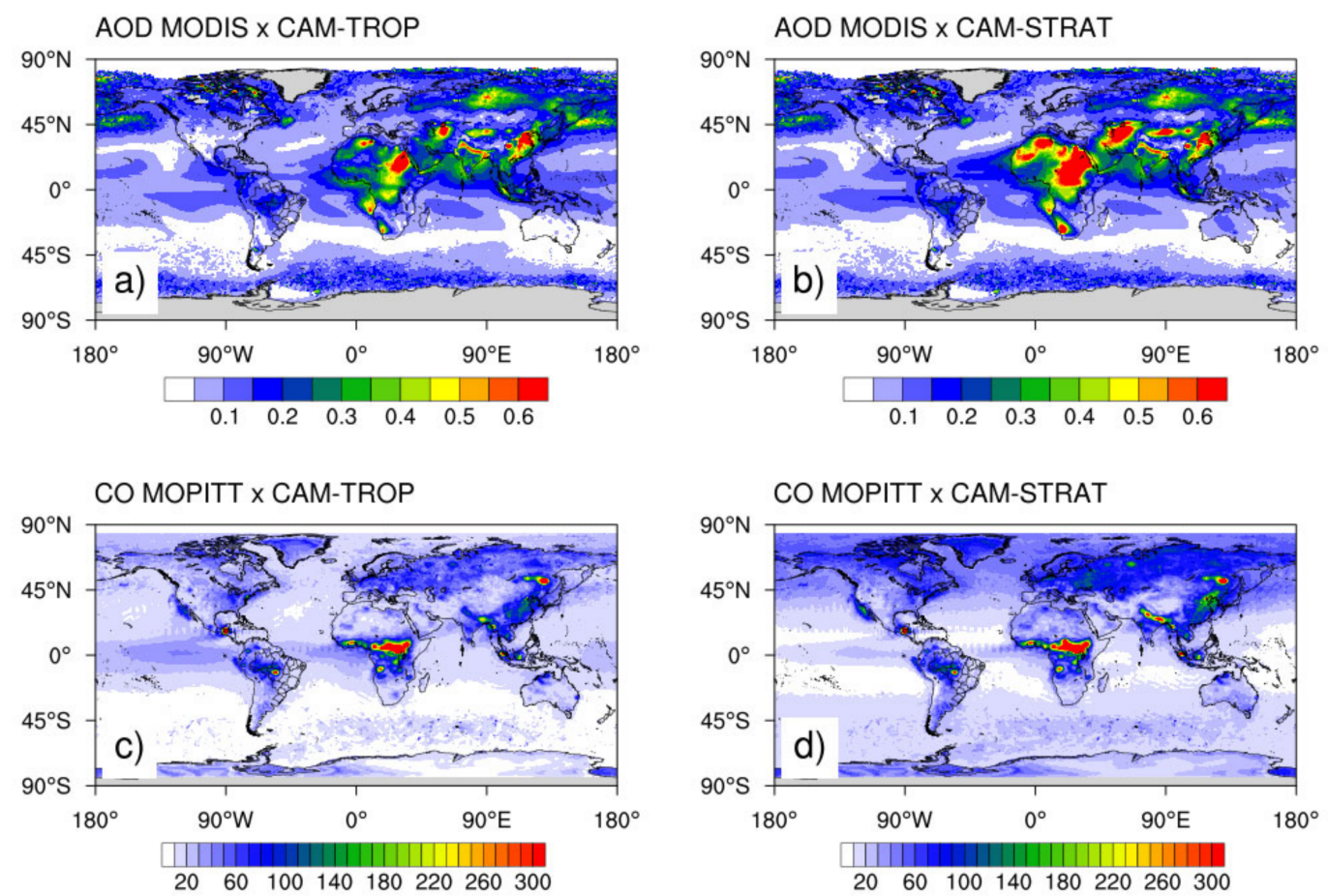

Figure 12. Root mean square error (RMSE) maps of annual average simulated AOD (a,b) and CO (ppb) (c,d) in both model configurations relative to the observations.

Figure 12c (tropospheric chemistry) and Figure 12d (tropospheric and stratospheric chemistry) show the RMSE between CO values of the CAM-chem model. Low RMSE values were obtained over most regions, except on the border of Mexico and Guatemala in Central America, Northern Mato Grosso state in Brazil, Central Africa, Northeast India, eastern Russia and Singapore.

Differences between observations both from the MODIS AOD and MOPITT CO to the model simulations can also be attributed to the uncertainties in the emission files used as input data in the CAM-chem model. For the period of the simulation considered in this study-i.e., 2009-2014, with 2009 regarded as the initialization time for the model一the emission files available as input to run the model are representative of the year 2000. It is important that studies with models using different emission inventories as input data are carried out and compared with observed data for aerosols and pollutant gases.

Table 3 shows the results for the global seasonal mean and standard deviation for $\mathrm{CO}$ and AOD observed from MOPITT and MODIS (Terra and Aqua), respectively, and global the seasonal mean and standard deviation for CO and AOD with the CAM5-MAM3 model using tropospheric chemistry and tropospheric/stratospheric chemistry mechanisms for the period of DJF, MAM, JJA, ASO and SON in 2010-2014.

Table 3. Global Annual means and standard deviations for CO (ppbv) and AOD observed from MOPITT and MODIS (Terra and Aqua), respectively, and for CO and AOD by the CAM5-MAM3 model with tropospheric chemistry and tropospheric/stratospheric chemistry mechanisms for the period from 2010 to 2014.

\begin{tabular}{ccccccc}
\hline & $\begin{array}{c}\text { CO } \\
\text { (Observed) }\end{array}$ & $\begin{array}{c}\text { CO } \\
\text { (Modeled) } \\
\text { TROPMAM }\end{array}$ & $\begin{array}{c}\text { CO } \\
\text { (Modeled) } \\
\text { STRATMAM }\end{array}$ & $\begin{array}{c}\text { AOD } \\
\text { (Observed) }\end{array}$ & $\begin{array}{c}\text { AOD } \\
\text { (Modeled) } \\
\text { TROPMAM }\end{array}$ & $\begin{array}{c}\text { AOD } \\
\text { SModeled) } \\
\text { SSTRATMAM }\end{array}$ \\
\hline DJF & $98.62 \pm 1.17$ & $94.44 \pm 4.65$ & $93.73 \pm 4.10$ & $0.16 \pm 0.02$ & $0.10 \pm 0.02$ & $0.13 \pm 0.02$ \\
MAM & $97.71 \pm 0.84$ & $99.76 \pm 2.99$ & $98.61 \pm 2.70$ & $0.18 \pm 0.02$ & $0.12 \pm 0.02$ & $0.15 \pm 0.03$ \\
JJA & $93.63 \pm 0.70$ & $93.42 \pm 2.77$ & $91.93 \pm 2.67$ & $0.19 \pm 0.02$ & $0.15 \pm 0.02$ & $0.18 \pm 0.03$ \\
SON & $98.03 \pm 0.81$ & $95.18 \pm 2.95$ & $93.95 \pm 2.46$ & $0.16 \pm 0.02$ & $0.11 \pm 0.02$ & $0.13 \pm 0.02$ \\
ASO & $98.77 \pm 0.76$ & $96.68 \pm 3.10$ & $95.31 \pm 2.65$ & $0.18 \pm 0.02$ & $0.13 \pm 0.02$ & $0.15 \pm 0.02$ \\
\hline
\end{tabular}


The high $\mathrm{CO}$ average found in the MAM period can be attributed mainly due to the high concentration for the entire Northern Hemisphere, mainly in eastern Asia (China). Higher concentrations of aerosols in JJA are found due to dust in desert regions in the Northern Hemisphere and also during the ASO period due to biomass burning in South America and South Africa.

In general, both versions of the model accurately represented the spatial and temporal distribution of CO. The global seasonal and annual cycles are reasonably represented by the model, as observed in Figures 1-5. Both versions of the model yield a positive correlation between 0.4 and 0.8 for almost the entire globe, except for the eastern USA and California Bay, south-central Argentina and the Sahel region in Africa and East Asia, where the correlation is negative. There are a few differences in the concentrations of surface $\mathrm{CO}$ from the results of simulation using the model with mechanisms of reactions in the troposphere and also including 28 photolysis reactions in the stratosphere.

In summary, both versions of the model reasonably represented the spatial and temporal distribution of AOD. Overall, the correlation is between 0.3 and 0.8 , except for the North and South Pacific Ocean, South Atlantic, the Indian Ocean, South Africa, Southern Australia, countries in Southeast Asia such as the Philippines and Indonesia, where the correlation is lower or negative. In both experiments, AOD levels were overestimated over the desert regions of Africa and the Middle East in all seasons but significantly underestimated over eastern China and northern India. CAM-STRATMAM overestimates the levels much more than CAM-TROPMAM over Africa.

In DJF, in general, aerosol concentration is lower over the globe, except for the far north of India and eastern China, where it is higher due to pollution generated by vehicular, thermoelectric, and industrial emissions. Also is higher in the transition from savannas to tropical forests in Africa due to biomass burning.

Observing Figures 11 and 12, correlation coefficient and RMSE, the model has a better ability to represent $\mathrm{CO}$ than aerosols, probably the operation and better calibration of the chemistry module in the MOZART model than the MAM3 aerosol module.

The two experiments were carried out over 6 years with monthly outputs, considering the first year as initialization (2009). The experiment that also included stratospheric chemistry had a simulation time that was four hours longer, using the same number of processors.

\subsection{FRP vs. CO vs. AOD Correlation}

Figure 13 shows the FRP pattern during DJF, MAM, JJA, ASO and SON (in W m ${ }^{-2}$ ) from the MODIS (Aqua) sensor with seasonal global averages and standard deviations of $1.14 \pm 0.62,1.47 \pm 0.74,1.58 \pm 0.92,1.83 \pm 0.91$ and $1.97 \pm 0.96$, respectively. DJF shows the highest values in southeast Asia (Indochina region), in countries such as Vietnam and Laos, among other agricultural-based countries, where $70 \%$ of the population live in rural areas. Besides, we highlight southeast China as a region prevailing agricultural activity in the tropical zone.

Several studies using small experimental fires demonstrated that the total FRP released over the lifetime of a fire has a simple linear relationship with the total amount of consumed fuel biomass [101]. On the northern coast of Australia, fires occur in the densely forested portion near the region of the islands of Indonesia except during DJF and MAM. The African continent has generally moderate values of FRP during DJF and MAM, but higher values are observed over South Africa, Angola, the southern part of the Republic of Congo, South Sudan, Chad and the border of Guinea with Senegal during JJA, SON. Africa is said to be the largest continental source of biomass burning emissions, according to previous studies (c.f., [102]).

South America presents lower FRP during DJF and MAM, whereas the seasons of JJA, SON and ASO show high values of FRP over these regions. In South America, Brazil has high values of FRP, except for the state of Amazonas (the most preserved part of the Amazon Forest). High values are observed in the state of São Paulo, Mato Grosso, Bahia, 
Piauí, Maranhão and Tocantins, which belong to the axis of agricultural expansion and cattle raising in Brazil.

Biomass burning is one of the problems still present in South American agriculture. More than 600,000 square kilometers of forest have been lost since the 1970s, and the current trend predicts losses of up to $40 \%$ of the forest by 2050, when rains could be reduced by $21 \%$ in the dry season [103]. The forest is crucial for the water cycle and current precipitation values over the important agricultural regions of all center-south of Brazil, which may be negatively impacted. A scientific campaign by Brazilian and American researchers, called Green Ocean Amazon (GOAmazon), began testing the hypothesis published in Science that the pollution produced in the city of Manaus, in Amazonas state, is affecting the formation process of rain in the forest. The decrease in precipitation leads to fewer fires being put out, fueling this cycle, as more soot reaches the clouds. The problem is further aggravated by the fact that these particles end up being scattered to the central and southern portions of the country, which can also jeopardize the precipitation cycle in these regions. Machado explains that the Low-Level Jet, a stream of wind that transports the humidity of the Amazon to the center-south of Brazil, favoring precipitation [104]. According to this author, these winds would absorb more pollutants on their way to the south, especially from biomass burning, which would disturb the formation of precipitating clouds in the region.

Recent work shows that large emissions of particulate matter from fires alter the mechanisms of cloud formation and their growth and precipitation patterns, which can suppress the formation of shallow clouds and delay or even inhibit precipitation in large areas affected by the emissions of fires, which may represent hundreds or thousands of kilometers of emissions [105]. About $60 \%$ to $80 \%$ of the natural aerosol particles in the Amazon act as cloud condensation nuclei (CCN). The difference in the $\mathrm{CCN}$ concentration in the rainy season and in the dry season (from about 200 to $20,000 \mathrm{~cm}^{-3}$ particles) in large areas of the Amazon profoundly changes the microphysical properties of clouds. If the environment is relatively clean, there are few CCN. In the competition over existing water vapor, if there are some relatively large or water-soluble $\mathrm{CCN}$, they will grow rapidly, collide with the smaller ones and precipitate as rain. The cloud grows quickly, reaching a maximum height of 4 or $5 \mathrm{~km}$. If the atmosphere is polluted, with a larger number of $\mathrm{CCN}$, as in the burning season, the competition over available water vapor increases, and the droplets grow slowly as the cloud grows. Often, these clouds do not even precipitate in the form of rain; the drops evaporate before reaching a critical precipitation size, and the water, along with the aerosols, does not return to the ground but is carried away by the winds [106].

Regions in South America such as in Paraguay, Northern Bolivia, Northern Argentina, Southern Chile, Colombia and Venezuela also have high values of FRP. In the USA, there are higher values of FRP in the region of the Gulf of Mexico and in Florida peninsula.

Regarding the annual average correlations between CO and FRP and between AOD and FRP, for the period 2010-2014, Figure 14a,b show that the highest values of correlation are in less densely urbanized regions of the globe, particularly in the tropical latitudes. In Asia, correlation indexes between FRP and $\mathrm{CO}$ vary from 0.6 to 0.8 in areas such as Cambodia, Laos, Thailand, Myanmar, and Singapore, as well as central Siberia. There is a very high correlation in the extreme north of Australia and also in the African continent, in most tropical regions south of the Sahara Desert. In Central America, high correlations are found on the border between Guatemala and Mexico and in Cuba. In South America, some features stand out: high correlations between FRP and CO are found in the Western Amazon region, such as Rondônia, the south of Pará and Amazonas states and Acre, as well as in the borders of these states with Bolivia and Peru. This region corresponds to the deforestation arc located in the fringes of the Amazon Forest, where fires present a seasonal and interannual variability that is directly associated with land use and agriculture expansion. The most significant fire concentrations are found in areas of dense rainforest and deciduous seasonal forest, followed by shrub and arboreal vegetation (pasture, savanna 
and shrublands) and mosaics comprising (1) agriculture (50-70\%) and pasture, shrubland and forest (20-50\%) and (2) pasture, shrubland and forest (50-70\%) with agriculture (20-50\%).
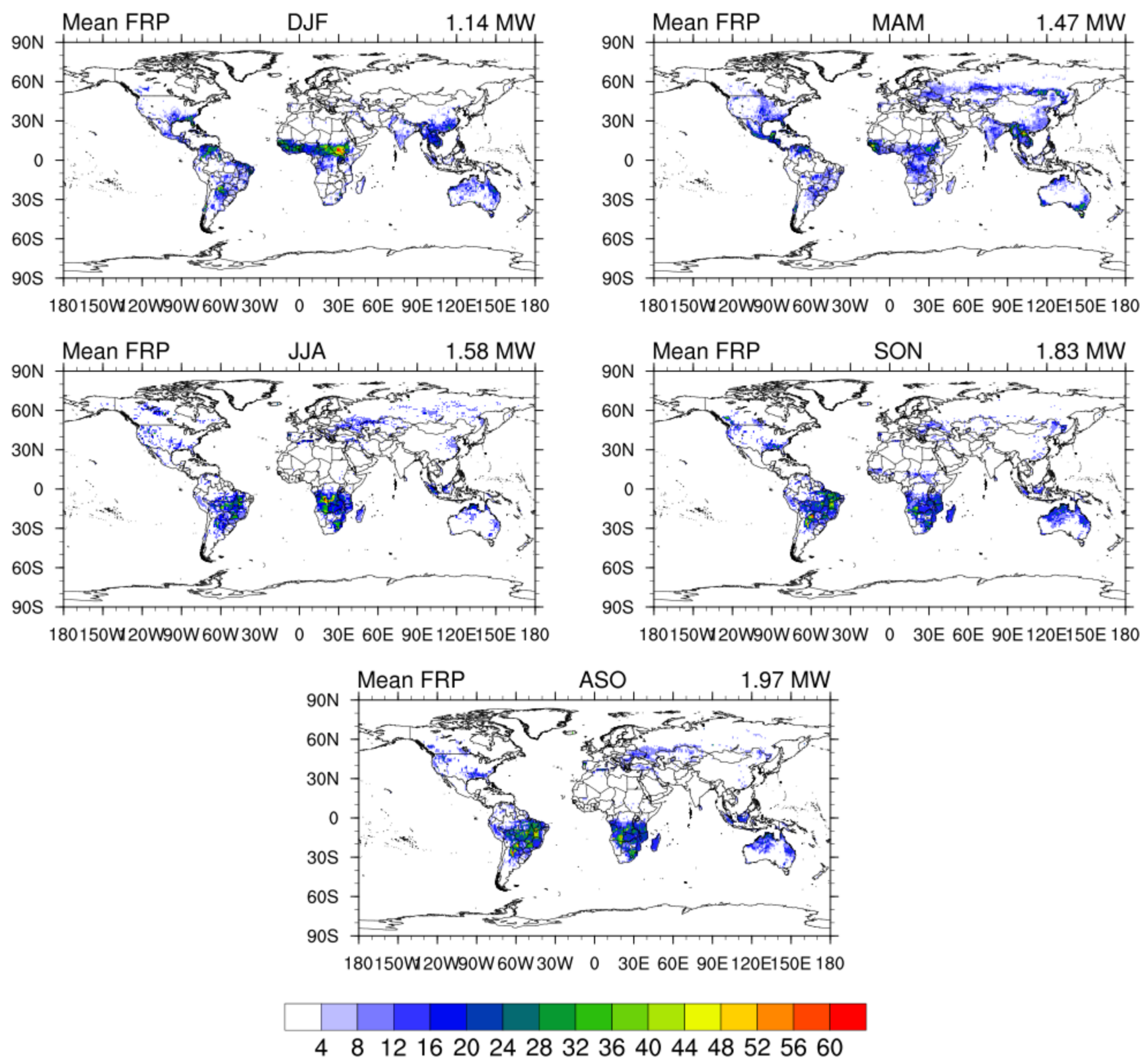

Figure 13. Seasonal mean fire radiative power (FRP) detected by the MODIS sensor with AQUA active fire products over the globe during DJF, MAM, JJA, SON and ASO from 2010 to 2014.

It can be presumed that these correlations around the globe reflect the occurrence of natural fires in remote regions, as well as of fires associated with agricultural activities. Figure 14c shows a correlation of 0.7 to 0.85 between CO and AOD in Southeast Asia in countries such as Laos, Myanmar and Singapore. There is also a strong correlation of $\mathrm{CO}$ and AOD in the extreme North of Australia, Indonesia, and Malaysia as well as over Mexico's border with Guatemala in Central America. In East and Central Africa, there is a high correlation between $\mathrm{CO}$ and aerosols from biomass burning from the transition environment between forest and savanna, and it is also possible to observe the transport of these pollutants from the African continent to the coast of Brazil. In South America, 
throughout Brazil, the correlation between $\mathrm{CO}$ and AOD is positive, as well as in countries bordering Brazil, such as Colombia, Peru, Bolivia, Paraguay and northern Argentina.
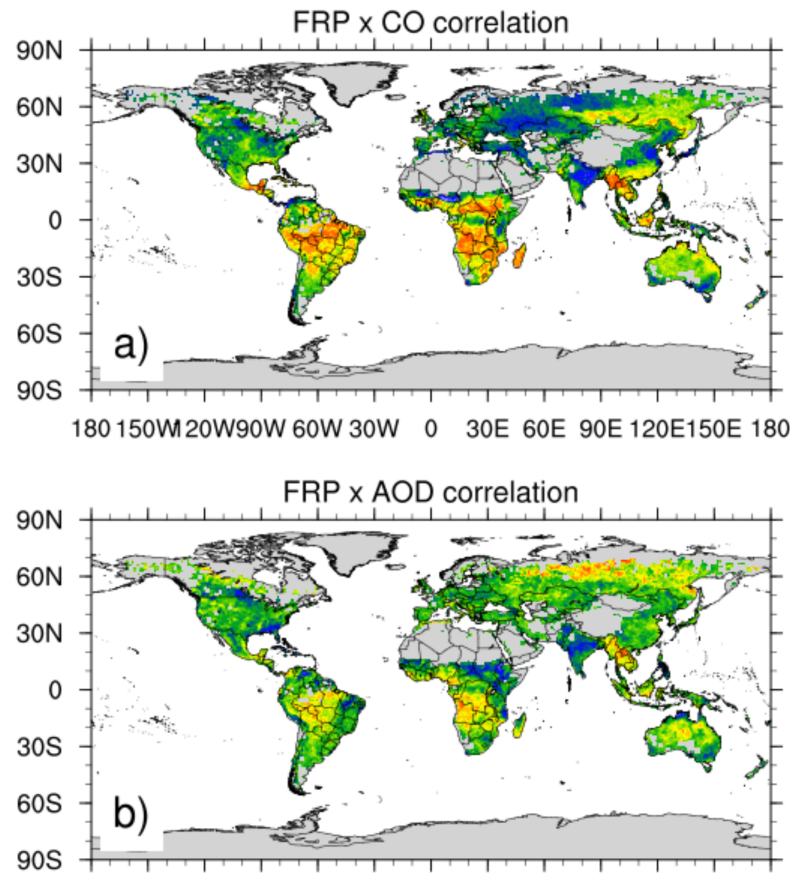

180150W20W90W 60W 30W O 30E 60E 90E 120E150E 180

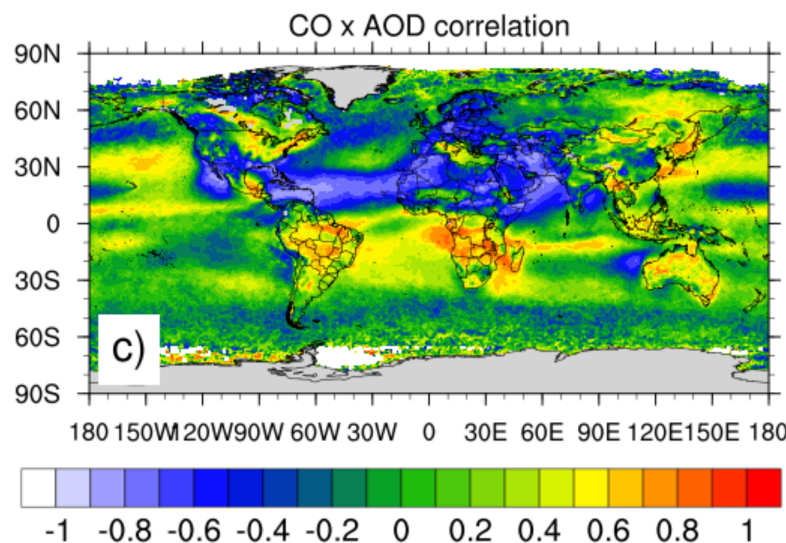

Figure 14. (a) Correlation coefficient between FRP (MW) MODIS and CO (ppb) from MOPITT, showing the highest prevalence of both parameters over the agricultural regions such as southeast Asia and southern China. (b) Correlation coefficient between FRP (MW) with AOD from MODIS, showing a positive correlation over less dense regions such as forested and agricultural lands across the globe. (c) Correlation coefficient of CO from MOPITT (ppb) with AOD from MODIS, showing different trends compared to correlations between FRP and CO and FRP and AOD $(\mathbf{a}, \mathbf{b})$. The AOD prevalence is higher in the tropical and sub-tropical regions.

As can be seen in Figure 14a,b, although many regions demonstrate strong correlations between CO and FRP and also between FRP and AOD, they may occur in spatially distinct forms. Depending on the type of vegetation and climate conditions, an increased CO concentration and/or aerosols may be favored. For example, in the Northern Hemisphere, the correlation between FRP and AOD (Figure 14b) is higher at high latitudes compared to the correlation between FRP and CO (Figure 14a). We observed this in the regions of Siberia and Canada, whereas the correlations between FRP and CO are higher in tropical regions of South America, southeast Asia and central Africa concerning the correlations between FRP and AOD. Different regions are prone to different spatial temporal patterns of 
FRP measurements. MODIS FRP has already been used to show that Boreal fires in North America burn, on average, more intensely than in Russia [44,107]. The negative correlation between FRP and AOD in Figure 14b may be related to places with a high concentration of biogenic aerosols such as sea salt transported from the ocean to the continent, dust, organic aerosols emitted by plants and secondary organic aerosols (SOA) derived from biogenic volatile organic compounds (VOCs). According to emission estimates, approximately 73\% of global aerosols come from biogenic sources [108-110].

\section{Conclusions}

The objective of this study was to investigate and compare global simulations of carbon monoxide (CO) and aerosol optical depth (AOD), performed with the CAM-chem model, against observed satellite data and, additionally, to explore the empirical relationship between $\mathrm{CO}, \mathrm{AOD}$ and fire radiative power (FRP).

Two different model configurations were used: (1) using tropospheric chemistry only and (2) including both tropospheric and stratospheric chemistry. The main findings are summarized as follows:

(1) In the Northern Hemisphere, the highest AOD concentrations are observed during March-April-May and June-July-August. In the Southern Hemisphere, the highest AOD concentrations are observed mainly during August-September-October. Over South America, the highest AOD values are observed over subtropical Brazil, Paraguay and Bolivia.

(2) Although both configurations of the model reasonably simulated the spatial and temporal distributions of CO and AOD concentrations, the model has difficulty in capturing the exact location of the maxima of the seasonal AOD distributions. $\mathrm{CO}$ concentrations are overestimated over central China, central Africa and equatorial regions of the Atlantic and western Pacific Oceans. The inclusion of stratospheric chemistry resulted in a significant decrease in this positive bias, due to the $\mathrm{CO}$ dry deposition, which is not present in the configuration using only tropospheric chemistry, and also due to a greater $\mathrm{CO}$ loss resulting from the chemical reactions and a shorter lifetime of these species in this configuration. AOD is overestimated over desert regions of Africa, the Middle East and Asia in both experiments, but the positive bias is even higher in these regions in the version with added stratospheric chemistry. In contrast, AOD is underestimated over regions associated with high anthropogenic activity, such as eastern China and northern India. During the rapid industrialization in the previous decades, east Asia shows differences of up to $500 \%$ for CO emissions compared to the REAS and EDGAR version 4.2, as reported in [111].

(3) Both model configurations considered in this study resulted in an underestimation of the CO concentrations over Canada, Europe and Russia. There was no CO increase in the period of study in these regions, indicating that anthropogenic emissions may be underestimated. Both versions of the model show positive correlations between modeled and observed $\mathrm{CO}$ (ranging from 0.4 to 0.8 ) for the whole globe, except for the coast of California, south-central Argentina, the Sahel region and east Asia (where the correlation is negative).

(4) High correlations were observed between FRP and CO in the western Amazon region, such as in the Brazilian states of Rondônia, Acre, the south of Pará and Amazonas, as well as at the border between Brazil, Bolivia and Peru. This region corresponds to the deforestation arc located in the fringes of the Amazon Forest, where fires present a seasonal and interannual variability that is directly associated with land use change and agriculture expansion.

(5) High correlations were observed between $\mathrm{CO}$ and aerosols (AOD) from biomass burning at the transition between the forest and savanna environments over east and central Africa. It is also possible to observe the transport of these pollutants from the African continent to the Brazilian coast. 
(6) Savanna and Tropical forests, as in South America (western Amazon), Central America, Africa, Australia, and Southeast Asia, show a higher FRP x CO correlation than FRP x AOD. In contrast, boreal forests in Russia, particularly in Siberia, show a higher FRP $x$ AOD correlation compared to FRP $\times$ CO. This may be related to differences in vegetation, temperature, and humidity at the time of burning. In tropical forests, it is likely that CO production is favored compared to aerosols, and in temperate forests, aerosol production is more likely than $\mathrm{CO}$ when compared to tropical forests. On the east coast of the United States and the eastern border of the USA with Canada, there is a high correlation of $\mathrm{CO} \times \mathrm{AOD}$ and a low correlation between FRP with both $\mathrm{CO}$ and AOD. It also occurs in eastern China, on the border between China, Russia, Mongolia, North India, and China. Therefore, such emissions in these regions are not generated by forest fires but by thermoelectric industries, other types of industries, and vehicular emissions since these are densely populated regions.

Our results show that, in general, the seasonal and global distributions of the AOD and $\mathrm{CO}$ concentration are reasonably reproduced by the two configurations of CAM-chem. However, the model overestimates the results for AOD over desert regions of Africa, the Middle East, and Asia due probably to the overestimation of dust in these regions. This bias is even more significant in the version with tropospheric and stratospheric chemistry. Therefore, the CAM5-MAM3 with stratospheric chemistry, which requires more computational cost, does not improve the results for AOD over desert regions. On the other hand, in both experiments, AOD levels over eastern China and northern India are significantly underestimated, probably because the fire emissions and vehicle, industrial and thermoelectric emissions are underestimated in emission inventories used in the model. Probably, emissions of black carbon, primary and secondary organic carbon from anthropogenic sources, are also underestimated in the emission inventories used in the model.

With the increasing environmental degradation worldwide, particularly in tropical developing nations, such as in the Brazilian Amazon forest in recent years, it is crucial to understand and model such processes with high precision and accuracy. Global satellite products and models can provide important insights to better understand deforestation processes, their temporal and spatial dynamics and their consequences, which are key aspects to implement policies and take action in order to protect the environment.

Supplementary Materials: The following are available online at https:/ /www.mdpi.com/article/ 10.3390/rs13112231/s1, Figure S1: (a) CO (ppb) observed by MOPITT sensor for DJF, in the period of 2010-2014, (b) CO simulated by the CAM5-MAM3 model using tropospheric chemistry and (d) tropospheric/stratospheric chemistry mechanisms without calculating Equation (4). The right side of the figure shows the model difference minus the observation (MOPITT), (c) for tropospheric chemistry and (d) for tropospheric/stratospheric chemistry., Figure S2: (a) CO (ppb) observed by MOPITT sensor for MAM, in the period of 2010-2014, (b) CO simulated by the CAM5-MAM3 model using tropospheric chemistry and (d) tropospheric/stratospheric chemistry mechanisms without calculating Equation (4). The right side of the figure shows the model difference minus the observation (MOPITT), (c) for tropospheric chemistry and (d) for tropospheric/stratospheric chemistry., Figure S3: (a) CO (ppb) observed by MOPITT sensor for JJA, in the period of 2010-2014, (b) CO simulated by the CAM5-MAM3 model using tropospheric chemistry and (d) tropospheric/stratospheric chemistry mechanisms without calculating Equation (4). The right side of the figure shows the model difference minus the observation (MOPITT), (c) for tropospheric chemistry and (d) for tropospheric/stratospheric chemistry., Figure S4: (a) CO (ppb) observed by MOPITT sensor for SON, in the period of 2010-2014, (b) CO simulated by the CAM5-MAM3 model using tropospheric chemistry and (d) tropospheric/stratospheric chemistry mechanisms without calculating Equation (4). The right side of the figure shows the model difference minus the observation (MOPITT), (c) for tropospheric chemistry and (d) for tropospheric/stratospheric chemistry., Figure S5: (a) CO (ppb) observed by MOPITT sensor for ASO, in the period of 2010-2014, (b) CO simulated by the CAM5-MAM3 model using tropospheric chemistry and (d) tropospheric/stratospheric chemistry mechanisms without cal- 
culating Equation (4). The right side of the figure shows the model difference minus the observation (MOPITT), (c) for tropospheric chemistry and (d) for tropospheric/stratospheric chemistry.

Author Contributions: Study conception and design: D.S.A., J.B.C., M.T.S.D. and B.K. Acquisition of data: D.S.A., J.P., V.B.C. and P.Y.K. Analysis and interpretation of data: D.S.A., J.B.C., M.T.S.D., B.K., V.B.C. and A.F. Drafting of manuscript: D.S.A., J.B.C., M.T.S.D., B.K., A.F., J.P., V.B.C., D.L.H., C.B., S.M.C., P.N., S.N.F. and P.Y.K. Critical revision: J.B.C., M.T.S.D., B.K., A.F., D.L.H., C.B., S.M.C., P.N., S.N.F. and P.Y.K. All authors have read and agreed to the published version of the manuscript.

Funding: This research was funded by National Water Agency (ANA) and the Coordination for the Improvement of Higher Education Personnel (CAPES), grant number 88887.115872/2015-01 and CAPES, grant number 88881.148662/2017-01.

Informed Consent Statement: Not applicable.

Data Availability Statement: The AOD products can be accessed on the GIOVANNI NASA subset ordering web page https:/ / giovanni.gsfc.nasa.gov/giovanni, accessed on 20 May 2021. This work used V8 TIR-NIR a priori surface-level daytime CO data. MOPITT products are available from https: / / www2.acom. ucar.edu/mopitt accessed on 2 November 2020. MOPITT data can be downloaded from https: / / earthdata.nasa.gov /, accessed on 2 November 2020. The gridded MODIS active fire products are available from https://reason.gesdisc.eosdis.nasa.gov/data/Fire/MYD14CM1.005 /doc/README.MODIS_Fire_1deg.005.pdf accessed on 20 July 2019. The raw Level 2 MYD14 data sets used in this study are available in HDF format and accessible at https: / / search.earthdata.nasa. gov / search?q=MYD14CM1\&m=-54.88513370118847!-66.09375!0!1!0!0\%2C2, accessed on 20 July 2019.

Acknowledgments: The authors express their gratitude to the Agência Nacional de Águas (ANA) and Coordenação de Aperfeiçoamento de Pessoal de Nível Superior (CAPES) (National Water Agency (ANA) and the Coordination for the Improvement of Higher Education Personnel (CAPES)) for providing the post-doc fellowship for Débora Souza Alvim under contract number 88887.115872/2015-01, respectively, in relation to the project "Development of the Brazilian Earth System Model—BESM and Generation of Climate Change Scenarios, Looking For Studies of Impacts on Water Resources2785/2015" and CAPES (No. 88887.371883/2019-00) and CAPES for partially funding this work through the project CAPES/Modelagem (Grant number 88881.148662/2017-01), providing a post-doc fellowship for Jayant Pendharkar. Thanks go to NCAR for the availability of the CAM-chem model and NASA for the availability of the observed data.

Conflicts of Interest: The authors declare no conflict of interest.

\section{References}

1. Andreae, M.O.; Rosenfeld, D.; Artaxo, P.; Costa, A.A.; Frank, G.P.; Longo, K.M.; Silva-Dias, M.A.F. Smoking Rain Clouds over the Amazon. Science 2004, 303, 1337-1342. [CrossRef]

2. $\quad$ Freitas, S.R.; Longo, K.M.; Dias, M.A.F.S.; Dias, P.L.S.; Chatfield, R.; Prins, E.; Artaxo, P.; Grell, G.A.; Recuero, F.S. Monitoring the transport of biomass burning emissions in South America. Environ. Fluid Mech. 2005, 5, 135-167. [CrossRef]

3. Wu, S.; Mickley, L.J.; Kaplan, J.O.; Jacob, D.J. Impacts of changes in land use and land cover on atmospheric chemistry and air quality over the 21st century. Atmos. Chem. Phys. 2012, 12, 1597-1609. [CrossRef]

4. Susskind, J.; Barnet, C.; Blaisdell, J.; Iredell, L.; Keita, F.; Kouvaris, L.; Molnar, G.; Chahine, M. Accuracy of geophysical parameters derived from Atmospheric Infrared Sounder/Advanced Microwave Sounding Unit as a function of fractional cloud cover. J. Geophys. Res. 2006, 111. [CrossRef]

5. Xiong, X.; Barnet, C.D.; Zhuang, Q.; Machida, T.; Sweeney, C.; Patra, P.K. Mid-upper tropospheric methane in the high Northern Hemisphere: Spaceborne observations by AIRS, aircraft measurements, and model simulations. J. Geophys. Res. Space Phys. 2010, 115, 19309. [CrossRef]

6. Granier, C.; Bessagnet, B.; Bond, T.; D’Angiola, A.; Van Der Gon, H.D.; Frost, G.J.; Heil, A.; Kaiser, J.; Kinne, S.; Klimont, Z.; et al. Evolution of anthropogenic and biomass burning emissions of air pollutants at global and regional scales during the 1980-2010 period. Clim. Chang. 2011, 109, 163-190. [CrossRef]

7. Van Der Werf, G.R.; Randerson, J.T.; Giglio, L.; Van Leeuwen, T.T.; Chen, Y.; Rogers, B.M.; Mu, M.; Van Marle, M.J.E.; Morton, D.C.; Collatz, G.J.; et al. Global fire emissions estimates during 1997-2016. Earth Syst. Sci. Data 2017, 9, 697-720. [CrossRef]

8. Crutzen, P.J.; Andreae, M.O. Biomass Burning in the Tropics: Impact on Atmospheric Chemistry and Biogeochemical Cycles. Science 1990, 250, 1669-1678. [CrossRef]

9. Sinha, P.; Hobbs, P.V.; Yokelson, R.J.; Blake, D.R.; Gao, S. Distributions of trace gases and aerosols during the dry biomass burning season in southern Africa. J. Geophys. Res. Space Phys. 2003, 108, 4536. [CrossRef] 
10. Kganyago, M.; Shikwambana, L. Assessing Spatio-Temporal Variability of Wildfires and their Impact on Sub-Saharan Ecosystems and Air Quality Using Multisource Remotely Sensed Data and Trend Analysis. Sustainability 2019, 11, 6811. [CrossRef]

11. Bremer, H.; Kar, J.; Drummond, J.R.; Nichitu, F.; Zou, J.; Liu, J.; Gille, J.C.; Deeter, M.N.; Francis, G.; Ziskin, D.; et al. Spatial and temporal variation of MOPITT CO in Africa and South America: A comparison with SHADOZ ozone and MODIS aerosol. J. Geophys. Res. Space Phys. 2004, 109. [CrossRef]

12. Zheng, B.; Chevallier, F.; Yin, Y.; Ciais, P.; Fortems-Cheiney, A.; Deeter, M.N.; Parker, R.J.; Wang, Y.; Worden, H.M.; Zhao, Y. Global atmospheric carbon monoxide budget 2000-2017 inferred from multi-species atmospheric inversions. Earth Syst. Sci. Data 2019, 11, 1411-1436. [CrossRef]

13. Liu, J.; Drummond, J.R.; Li, Q.; Gille, J.C.; Ziskin, D.C. Satellite mapping of CO emission from forest fires in Northwest America using MOPITT measurements. Remote Sens. Environ. 2005, 95, 502-516. [CrossRef]

14. Zheng, B.; Chevallier, F.; Ciais, P.; Yin, Y.; Deeter, M.N.; Worden, H.M.; Wang, Y.; Zhang, Q.; He, K. Rapid decline in carbon monoxide emissions and export from East Asia between years 2005 and 2016. Environ. Res. Lett. 2018, 13, 044007. [CrossRef]

15. Yin, S.; Wang, X.; Zhang, X.; Guo, M.; Miura, M.; Xiao, Y. Influence of biomass burning on local air pollution in mainland Southeast Asia from 2001 to 2016. Environ. Pollut. 2019, 254, 112949. [CrossRef] [PubMed]

16. Paton-Walsh, C.; Deutscher, N.M.; Griffith, D.W.T.; Forgan, B.W.; Wilson, S.R.; Jones, N.B.; Edwards, D.P. Trace gas emissions from savanna fires in northern Australia. J. Geophys. Res. 2010, 115, 16314. [CrossRef]

17. Yurganov, L.N.; Duchatelet, P.; Dzhola, A.V.; Edwards, D.P.; Hase, F.; Kramer, I.; Mahieu, E.; Mellqvist, J.; Notholt, J.; Novelli, P.C.; et al. Increased Northern Hemispheric carbon monoxide burden in the troposphere in 2002 and 2003 detected from the ground and from space. Atmos. Chem. Phys. Discuss. 2005, 5, 563-573. [CrossRef]

18. Levine, J.S.; Iii, W.R.C.; Winsted, E.L.; Stocks, B.J. Biomass Burning and Global Change; AIP Publishing: Melville, NY, USA, 1992; Volume 277, pp. 131-139.

19. Burling, I.R.; Yokelson, R.J.; Griffith, D.W.T.; Johnson, T.J.; Veres, P.; Roberts, J.M.; Warneke, C.; Urbanski, S.P.; Reardon, J.; Weise, D.R.; et al. Laboratory measurements of trace gas emissions from biomass burning of fuel types from the southeastern and southwestern United States. Atmos. Chem. Phys. Discuss. 2010, 10, 11115-11130. [CrossRef]

20. Kaufman, Y.J.; Tucker, C.J.; Fung, I. Remote sensing of biomass burning in the tropics. J. Geophys. Res. Athmos. 1990, 95, 9927-9939. [CrossRef]

21. Pereira, G.; Freitas, S.R.; Moraes, E.C.; Ferreira, N.J.; Shimabukuro, Y.E.; Rao, V.B.; Longo, K.M. Estimating trace gas and aerosol emissions over South America: Relationship between fire radiative energy released and aerosol optical depth observations. Atmos. Environ. 2009, 43, 6388-6397. [CrossRef]

22. Kaufman, Y.J.; Kleidman, R.G.; King, M.D. SCAR-B fires in the tropics: Properties and remote sensing from EOS-MODIS. J. Geophys. Res. Space Phys. 1998, 103, 31955-31968. [CrossRef]

23. Kaufman, Y.J.; Justice, C.O.; Flynn, L.P.; Kendall, J.D.; Prins, E.M.; Giglio, L.; Ward, D.E.; Menzel, W.P.; Setzer, A.W. Potential global fire monitoring from EOS-MODIS. J. Geophys. Res. Atmos. 1998, 103, 32215-32238. [CrossRef]

24. Artaxo, P.; Martins, J.V.; Yamasoe, M.; Procópio, A.S.; Pauliquevis, T.; Andreae, M.O.; Guyon, P.; Gatti, L.V.; Leal, A.M.C. Physical and chemical properties of aerosols in the wet and dry seasons in Rondônia, Amazonia. J. Geophys. Res. Space Phys. 2002, 107, LBA 49-1. [CrossRef]

25. Jacobson, M.Z. Atmospheric Pollution: History, Science, and Regulation, 1st ed.; Cambridge University Press: New York, NY, USA, 2002; ISBN 978-0-521-01044-3.

26. Rosenfeld, D. TRMM observed first direct evidence of smoke from forest fires inhibiting rainfall. Geophys. Res. Lett. 1999, 26, 3105-3108. [CrossRef]

27. Sarangi, C.; Tripathi, S.N.; Kanawade, V.P.; Koren, I.; Pai, D.S. Investigation of the aerosol-cloud-rainfall association over the Indian summer monsoon region. Atmos. Chem. Phys. Discuss. 2017, 17, 5185-5204. [CrossRef]

28. Collins, W.D.; Rasch, P.J.; Eaton, B.E.; Khattatov, B.V.; Lamarque, J.-F.; Zender, C. Simulating aerosols using a chemical transport model with assimilation of satellite aerosol retrievals: Methodology for INDOEX. J. Geophys. Res. Space Phys. 2001, 106, 7313-7336. [CrossRef]

29. Barbu, A.L.; Segers, A.J.; Schaap, M.; Heemink, A.W.; Builtjes, P.J.H. A multi-component data assimilation experiment directed to sulphur dioxide and sulphate over Europe. Atmos. Environ. 2009, 43, 1622-1631. [CrossRef]

30. Bocquet, M.; Elbern, H.; Eskes, H.; Hirtl, M.; Žabkar, R.; Carmichael, G.R.; Flemming, J.; Inness, A.; Pagowski, M.; Camaño, J.L.P.; et al. Data assimilation in atmospheric chemistry models: Current status and future prospects for coupled chemistry meteorology models. Atmos. Chem. Phys. 2015, 15, 5325-5358. [CrossRef]

31. Neto, O.L.D.M.; Coutinho, M.M.; Marengo, J.A.; Capistrano, V.B. The impacts of a plume-rise scheme on earth system modeling: Climatological effects of biomass aerosols on the surface temperature and energy budget of South America. Theor. Appl. Clim. 2017, 129, 1035-1044. [CrossRef]

32. Wang, H.; Naghavi, M.; Allen, C.; Barber, R.M.; Bhutta, Z.A.; Casey, D.C.; Charlson, F.J.; Chen, A.Z.; Coates, M.M.; Coggeshall, M.; et al. Global, regional, and national life expectancy, all-cause mortality, and cause-specific mortality for 249 causes of death, 1980-2015: A systematic analysis for the Global Burden of Disease Study 2015. Lancet 2016, 388, 1459-1544. [CrossRef]

33. Klimont, Z.; Kupiainen, K.; Heyes, C.; Purohit, P.; Cofala, J.; Rafaj, P.; Borken-Kleefeld, J.; Schöpp, W. Global anthropogenic emissions of particulate matter including black carbon. Atmos. Chem. Phys. Discuss. 2017, 17, 8681-8723. [CrossRef] 
34. Worden, H.M.; Deeter, M.N.; Frankenberg, C.; George, M.; Nichitiu, F.; Worden, J.; Aben, I.; Bowman, K.W.; Clerbaux, C.; Coheur, P.-F.; et al. Decadal record of satellite carbon monoxide observations. Atmos. Chem. Phys. 2013, 13, 837-850. [CrossRef]

35. Deeter, M.N.; Martínez-Alonso, S.; Edwards, D.P.; Emmons, L.K.; Gille, J.C.; Worden, H.M.; Sweeney, C.; Pittman, J.V.; Daube, B.C.; Wofsy, S.C. The MOPITT Version 6 product: Algorithm enhancements and validation. Atmos. Meas. Tech. 2014, 7, 3623-3632. [CrossRef]

36. Edwards, D.P.; Halvorson, C.M.; Gille, J.C. Radiative transfer modeling for the EOS Terra satellite Measurement of Pollution in the Troposphere (MOPITT) instrument. J. Geophys. Res. 1999, 104, 16755-16775. [CrossRef]

37. Deeter, M.N.; Emmons, L.K.; Francis, G.L.; Edwards, D.P.; Gille, J.C.; Warner, J.; Khattatov, B.V.; Ziskin, D.; Lamarque, J.; Ho, S.; et al. Operational carbon monoxide retrieval algorithm and selected results for the MOPITT instrument. J. Geophys. Res. Space Phys. 2003, 108. [CrossRef]

38. Emmons, L.K.; Edwards, D.P.; Deeter, M.N.; Gille, J.C.; Campos, T.; Nedelec, P.; Novelli, P.; Sachse, G. Measurements of Pollution In The Troposphere (MOPITT) validation through 2006. Atmos. Chem. Phys. 2009, 9, 1795-1803. [CrossRef]

39. Drummond, J.R.; Zou, J.; Nichitiu, F.; Kar, J.; Deschambaut, R.; Hackett, J. A review of 9-year performance and operation of the MOPITT instrument. Adv. Space Res. 2010, 45, 760-774. [CrossRef]

40. Deeter, M.N.; Martínez-Alonso, S.; Gatti, L.V.; Gloor, M.; Miller, J.B.; Domingues, L.G.; Correia, C.S.C. Validation and analysis of MOPITT CO observations of the Amazon Basin. Atmos. Meas. Tech. 2016, 9, 3999-4012. [CrossRef]

41. Buchholz, R.R.; Deeter, M.N.; Worden, H.M.; Gille, J.; Edwards, D.P.; Hannigan, J.W.; Jones, N.B.; Paton-Walsh, C.; Griffith, D.W.T.; Smale, D.; et al. Validation of MOPITT carbon monoxide using ground-based Fourier transform infrared spectrometer data from NDACC. Atmos. Meas. Tech. 2017, 10, 1927-1956. [CrossRef]

42. Heald, C.L.; Jacob, D.J.; Jones, D.B.A.; Palmer, P.I.; Logan, J.A.; Streets, D.G.; Sachse, G.W.; Gille, J.C.; Hoffman, R.N.; Nehrkorn, T. Comparative inverse analysis of satellite (MOPITT) and aircraft (TRACE-P) observations to estimate Asian sources of carbon monoxide. J. Geophys. Res. Atmos. 2004, 109. [CrossRef]

43. Miyazaki, K.; Eskes, H.J.; Sudo, K.; Takigawa, M.; Van Weele, M.; Boersma, K.F. Simultaneous assimilation of satellite $\mathrm{NO}_{2}$, $\mathrm{O}_{3}$, $\mathrm{CO}$, and $\mathrm{HNO}_{3}$ data for the analysis of tropospheric chemical composition and emissions. Atmos. Chem. Phys. Discuss. 2012, 12, 9545-9579. [CrossRef]

44. Giglio, L.; Csiszar, I.; Justice, C.O. Global distribution and seasonality of active fires as observed with the Terra and Aqua Moderate Resolution Imaging Spectroradiometer (MODIS) sensors. J. Geophys. Res. Space Phys. 2006, 111. [CrossRef]

45. Justice, C.; Giglio, L.; Korontzi, S.; Owens, J.; Morisette, J.; Roy, D.; Descloitres, J.; Alleaume, S.; Petitcolin, F.; Kaufman, Y. The MODIS fire products. Remote Sens. Environ. 2002, 83, 244-262. [CrossRef]

46. Remer, L.A.; Kaufman, Y.J.; Tanré, D.; Mattoo, S.; Chu, D.A.; Martins, J.V.; Li, R.R.; Ichoku, C.; Levy, R.C.; Kleidman, R.G.; et al. The MODIS Aerosol Algorithm, Products, and Validation. J. Atmos. Sci. 2005, 62, 947-973. [CrossRef]

47. Kaufman, Y.J.; Tanré, D.; Boucher, O. A Satellite View of Aerosols in the Climate System. Nature 2002, 419, 215-223. [CrossRef] [PubMed]

48. Platnick, S.; King, M.; Ackerman, S.; Menzel, W.P.; Baum, B.; Riedi, J.; Frey, R. The MODIS cloud products: Algorithms and examples from terra. IEEE Trans. Geosci. Remote Sens. 2003, 41, 459-473. [CrossRef]

49. Ignatov, A.; Minnis, P.; Miller, W.F.; Wielicki, B.A.; Remer, L. Consistency of global MODIS aerosol optical depths over ocean on Terra and Aqua CERES SSF data sets. J. Geophys. Res. 2006, 111. [CrossRef]

50. Wei, J.; Li, Z.; Peng, Y.; Sun, L. MODIS Collection 6.1 aerosol optical depth products over land and ocean: Validation and comparison. Atmos. Environ. 2019, 201, 428-440. [CrossRef]

51. Wei, J.; Li, Z.; Sun, L.; Peng, Y.; Liu, L.; He, L.; Qin, W.; Cribb, M. MODIS Collection 6.13 km resolution aerosol optical depth product: Global evaluation and uncertainty analysis. Atmos. Environ. 2020, 240, 117768. [CrossRef]

52. Bilal, M.; Nazeer, M.; Nichol, J.; Qiu, Z.; Wang, L.; Bleiweiss, M.P.; Shen, X.; Campbell, J.R.; Lolli, S. Evaluation of Terra-MODIS C6 and C6.1 Aerosol Products against Beijing, XiangHe, and Xinglong AERONET Sites in China during 2004-2014. Remote Sens. 2019, 11, 486. [CrossRef]

53. Sharma, V.; Ghosh, S.; Bilal, M.; Dey, S.; Singh, S. Performance of MODIS C6.1 Dark Target and Deep Blue aerosol products in Delhi National Capital Region, India: Application for aerosol studies. Atmos. Pollut. Res. 2021, 12, 65-74. [CrossRef]

54. Wang, Y.; Yuan, Q.; Li, T.; Shen, H.; Zheng, L.; Zhang, L. Evaluation and comparison of MODIS Collection 6.1 aerosol optical depth against AERONET over regions in China with multifarious underlying surfaces. Atmos. Environ. 2019, 200, $280-301$. [CrossRef]

55. Jones, T.A.; Christopher, S.A.; Quaas, J. A six year satellite-based assessment of the regional variations in aerosol indirect effects. Atmos. Chem. Phys. 2009, 9, 4091-4114. [CrossRef]

56. Floutsi, A.A.; Carraca, M.B.K.; Matsoukas, C.; Hatzianastassiou, N.; Biskos, G. The regime of Aerosol Optical Depth and Ångström exponent over Central and South Asia. E3S Web Conf. 2019, 99, 01003. [CrossRef]

57. Sherman, J.P.; Gupta, P.; Levy, R.C.; Sherman, P.J. An Evaluation of MODIS-Retrieved Aerosol Optical Depth over a Mountainous AERONET Site in the Southeastern US. Aerosol Air Qual. Res. 2016, 16, 3243-3255. [CrossRef]

58. Glantz, P.; Freud, E.; Johansson, C.; Noone, K.J.; Tesche, M. Trends in MODIS and AERONET derived aerosol optical thickness over Northern Europe. Tellus B Chem. Phys. Meteorol. 2019, 71, 1-20. [CrossRef] 
59. Emmons, L.K.; Walters, S.; Hess, P.G.; Lamarque, J.-F.; Pfister, G.G.; Fillmore, D.; Granier, C.; Guenther, A.; Kinnison, D.; Laepple, T.; et al. Description and evaluation of the Model for Ozone and Related chemical Tracers, version 4 (MOZART-4). Geosci. Model. Dev. 2010, 3, 43-67. [CrossRef]

60. Lamarque, J.-F.; Emmons, L.K.; Hess, P.G.; Kinnison, D.E.; Tilmes, S.; Vitt, F.; Heald, C.L.; Holland, E.A.; Lauritzen, P.H.; Neu, J.; et al. CAM-chem: Description and evaluation of interactive atmospheric chemistry in the Community Earth System Model. Geosci. Model. Dev. 2012, 5, 369-411. [CrossRef]

61. Zhang, G.; McFarlane, N.A. Sensitivity of climate simulations to the parameterization of cumulus convection in the Canadian climate centre general circulation model. Atmos. Ocean. 1995, 33, 407-446. [CrossRef]

62. Park, S.; Bretherton, C.S. The University of Washington Shallow Convection and Moist Turbulence Schemes and Their Impact on Climate Simulations with the Community Atmosphere Model. J. Clim. 2009, 22, 3449-3469. [CrossRef]

63. Jonson, J.E.; Stohl, A.; Fiore, A.; Hess, P.; Szopa, S.; Wild, O.; Zeng, G.; Dentener, F.J.; Lupu, A.; Schultz, M.G.; et al. A multi-model analysis of vertical ozone profiles. Atmos. Chem. Phys. Discuss. 2010, 10, 5759-5783. [CrossRef]

64. Shindell, D.T.; Chin, M.; Dentener, F.; Doherty, R.M.; Faluvegi, G.; Fiore, A.; Hess, P.; Koch, D.M.; MacKenzie, I.A.; Sanderson, M.G.; et al. A multi-model assessment of pollution transport to the Arctic. Atmos. Chem. Phys. 2008, 8, 5353-5372. [CrossRef]

65. Tilmes, S.; Lamarque, J.-F.; Emmons, L.K.; Kinnison, D.E.; Ma, P.-L.; Liu, X.; Ghan, S.; Bardeen, C.; Arnold, S.; Deeter, M.; et al. Description and evaluation of tropospheric chemistry and aerosols in the Community Earth System Model (CESM1.2). Geosci. Model. Dev. 2015, 8, 1395-1426. [CrossRef]

66. Morrison, H.; Gettelman, A. A New Two-Moment Bulk Stratiform Cloud Microphysics Scheme in the Community Atmosphere Model, Version 3 (CAM3). Part I: Description and Numerical Tests. J. Clim. 2008, 21, 3642-3659. [CrossRef]

67. Iacono, M.J.; Delamere, J.S.; Mlawer, E.J.; Shephard, M.W.; Clough, S.A.; Collins, W.D. Radiative forcing by long-lived greenhouse gases: Calculations with the AER radiative transfer models. J. Geophys. Res. 2008, 113, 113. [CrossRef]

68. Liu, X.; Easter, R.C.; Ghan, S.J.; Zaveri, R.A.; Rasch, P.J.; Shi, X.; Lamarque, J.-F.; Gettelman, A.; Morrison, H.F.; Vitt, F.M.; et al. Toward a minimal representation of aerosols in climate models: Description and evaluation in the Community Atmosphere Model CAM5. Geosci. Model. Dev. 2012, 5, 709-739. [CrossRef]

69. Guenther, A.; Karl, T.; Harley, P.; Wiedinmyer, C.; Palmer, P.I.; Geron, C. Estimates of global terrestrial isoprene emissions using MEGAN (Model of Emissions of Gases and Aerosols from Nature). Atmos. Chem. Phys. Discuss. 2006, 6, 3181-3210. [CrossRef]

70. Guenther, A.B.; Jiang, X.; Heald, C.L.; Sakulyanontvittaya, T.; Duhl, T.; Emmons, L.K.; Wang, X. The Model of Emissions of Gases and Aerosols from Nature version 2.1 (MEGAN2.1): An extended and updated framework for modeling biogenic emissions. Geosci. Model. Dev. 2012, 5, 1471-1492. [CrossRef]

71. Wiedinmyer, C.; Quayle, B.; Geron, C.; Belote, A.; McKenzie, D.; Zhang, X.; O’Neill, S.; Wynne, K.K. Estimating emissions from fires in North America for air quality modeling. Atmos. Environ. 2006, 40, 3419-3432. [CrossRef]

72. Wiedinmyer, C.; Akagi, S.K.; Yokelson, R.J.; Emmons, L.K.; AlSaadi, J.A.; Orlando, J.J.; Soja, A.J. The Fire INventory from NCAR (FINN): A high resolution global model to estimate the emissions from open burning. Geosci. Model. Dev. 2011, 4, 625-641. [CrossRef]

73. Bond, T.C.; Streets, D.; Yarber, K.F.; Nelson, S.M.; Woo, J.; Klimont, Z. A technology-based global inventory of black and organic carbon emissions from combustion. J. Geophys. Res. Space Phys. 2004, 109, D14203. [CrossRef]

74. Ohara, T.; Akimoto, H.; Kurokawa, J.; Horii, N.; Yamaji, K.; Yan, X.; Hayasaka, T. An Asian emission inventory of anthropogenic emission sources for the period 1980-2020. Atmos. Chem. Phys. Discuss. 2007, 7, 4419-4444. [CrossRef]

75. Kloster, S.; Feichter, J.; Maier-Reimer, E.; Six, K.D.; Stier, P.; Wetzel, P. DMS cycle in the marine ocean-atmosphere system-A global model study. Biogeosciences 2006, 3, 29-51. [CrossRef]

76. Andres, R.J.; Kasgnoc, A.D. A time-averaged inventory of subaerial volcanic sulfur emissions. J. Geophys. Res. Space Phys. 1998, 103, 25251-25261. [CrossRef]

77. Marsh, D.R.; Mills, M.; Kinnison, D.E.; Lamarque, J.-F.; Calvo, N.; Polvani, L.M. Climate Change from 1850 to 2005 Simulated in CESM1(WACCM). J. Clim. 2013, 26, 7372-7391. [CrossRef]

78. Tilmes, S.; Lamarque, J.-F.; Emmons, L.K.; Kinnison, D.E.; Marsh, D.; Garcia, R.R.; Smith, A.; Neely, R.R.; Conley, A.; Vitt, F.; et al. Representation of the Community Earth System Model (CESM1) CAM4-chem within the Chemistry-Climate Model Initiative (CCMI). Geosci. Model. Dev. 2016, 9, 1853-1890. [CrossRef]

79. Alvim, D.S.; Pendharkar, J.; Capistrano, V.B.; Frassoni, A.; Enoré, D.P.; Neto, O.L.D.M.; Gutierrez, E.R.; Choudhury, A.D.; Kubota, P.Y.; Da Silva, J.; et al. Aerosol distribution over Brazil with ECHAM-HAM and CAM5-MAM3 simulations and its comparison with ground-based and satellite data. Atmos. Pollut. Res. 2017, 8, 718-728. [CrossRef]

80. Jiang, Z.; Jones, D.B.A.; Worden, J.; Worden, H.M.; Henze, D.K.; Wang, Y.X. Regional data assimilation of multi-spectral MOPITT observations of CO over North America. Atmos. Chem. Phys. Discuss. 2015, 15, 6801-6814. [CrossRef]

81. Kar, J.; Jones, D.B.A.; Drummond, J.R.; Attié, J.L.; Liu, J.; Zou, J.; Nichitiu, F.; Seymour, M.D.; Edwards, D.P.; Deeter, M.N.; et al. Measurement of low-altitude CO over the Indian subcontinent by MOPITT. J. Geophys. Res. Space Phys. 2008,113, D16307. [CrossRef]

82. Xu, C.; Duan, J.; Wang, Y.; Li, M.; Cheng, T.; Wang, H.; Zhu, H.; Xie, X.; Liu, Y.; Ling, Y.; et al. Effects of Wintertime Polluted Aerosol on Clouds over the Yangtze River Delta: Case Study. Aerosol Air Qual. Res. 2018, 18, 1799-1816. [CrossRef] 
83. Cheng, M.; Zhi, G.; Tang, W.; Liu, S.; Dang, H.; Guo, Z.; Du, J.; Du, X.; Zhang, W.; Zhang, Y.; et al. Air pollutant emission from the underestimated households' coal consumption source in China. Sci. Total. Environ. 2017, 580, 641-650. [CrossRef]

84. Zhi, G.; Zhang, Y.; Sun, J.; Cheng, M.; Dang, H.; Liu, S.; Yang, J.; Zhang, Y.; Xue, Z.; Li, S.; et al. Village energy survey reveals missing rural raw coal in northern China: Significance in science and policy. Environ. Pollut. 2017, 223, 705-712. [CrossRef]

85. Shindell, D.T.; Faluvegi, G.; Stevenson, D.S.; Krol, M.C.; Emmons, L.K.; Lamarque, J.-F.; Pétron, G.; Dentener, F.J.; Ellingsen, K.; Schultz, M.G.; et al. Multimodel simulations of carbon monoxide: Comparison with observations and projected near-future changes. J. Geophys. Res. Space Phys. 2006, 111, D19306. [CrossRef]

86. Yarragunta, Y.; Srivastava, S.; Mitra, D. Validation of lower tropospheric carbon monoxide inferred from MOZART model simulation over India. Atmos. Res. 2017, 184, 35-47. [CrossRef]

87. Naik, V.; Voulgarakis, A.; Fiore, A.M.; Horowitz, L.; Lamarque, J.-F.; Lin, M.; Prather, M.J.; Young, P.J.; Bergmann, D.; CameronSmith, P.J.; et al. Preindustrial to present-day changes in tropospheric hydroxyl radical and methane lifetime from the Atmospheric Chemistry and Climate Model Intercomparison Project (ACCMIP). Atmos. Chem. Phys. Discuss. 2013, 13, 5277-5298. [CrossRef]

88. Gaubert, B.; Arellano, A.F.; Barre, J.; Worden, H.M.; Emmons, L.K.; Tilmes, S.; Buchholz, R.; Vitt, F.; Raeder, K.; Collins, N.; et al. Toward a chemical reanalysis in a coupled chemistry-climate model: An evaluation of MOPITT CO assimilation and its impact on tropospheric composition. J. Geophys. Res. Atmos. 2016, 121, 7310-7343. [CrossRef]

89. Buchholz, R.R.; Hammerling, D.; Worden, H.M.; Deeter, M.N.; Emmons, L.K.; Edwards, D.P.; Monks, S.A. Links Between Carbon Monoxide and Climate Indices for the Southern Hemisphere and Tropical Fire Regions. J. Geophys. Res. Atmos. 2018, 123, 9786-9800. [CrossRef]

90. Querol, X.; Tobías, A.; Pérez, N.; Karanasiou, A.; Amato, F.; Stafoggia, M.; García-Pando, C.P.; Ginoux, P.; Forastiere, F.; Gumy, S.; et al. Monitoring the impact of desert dust outbreaks for air quality for health studies. Environ. Int. 2019, 130, 104867. [CrossRef] [PubMed]

91. Klingmüller, K.; Pozzer, A.; Metzger, S.; Stenchikov, G.L.; Lelieveld, J. Aerosol optical depth trend over the Middle East. Atmos. Chem. Phys. 2016, 16, 5063-5073. [CrossRef]

92. Habib, A.; Chen, B.; Khalid, B.; Tan, S.; Che, H.; Mahmood, T.; Shi, G.; Butt, M.T. Estimation and inter-comparison of dust aerosols based on MODIS, MISR and AERONET retrievals over Asian desert regions. J. Environ. Sci. 2019, 76, 154-166. [CrossRef] [PubMed]

93. Petetin, H.; Sauvage, B.; Parrington, M.; Clark, H.; Fontaine, A.; Athier, G.; Blot, R.; Boulanger, D.; Cousin, J.-M.; Nédélec, P.; et al. The role of biomass burning as derived from the tropospheric CO vertical profiles measured by IAGOS aircraft in $2002-2017$. Atmos. Chem. Phys. Discuss. 2018, 18, 17277-17306. [CrossRef]

94. Kumar, S.S.; Roy, D.P. Global operational land imager Landsat-8 reflectance-based active fire detection algorithm. Int. J. Digit. Earth 2017, 11, 154-178. [CrossRef]

95. Alves, N.D.O.; Brito, J.; Caumo, S.; Arana, A.; Hacon, S.D.S.; Artaxo, P.; Hillamo, R.; Teinilä, K.; De Medeiros, S.R.B.; Vasconcellos, P.D.C. Biomass burning in the Amazon region: Aerosol source apportionment and associated health risk assessment. Atmos. Environ. 2015, 120, 277-285. [CrossRef]

96. Yang, P.; Yi, B.; Bowman, K.P.; Liu, X. Aerosol-cloud-precipitation relationships from satellite observations and global climate model simulations. J. Appl. Remote Sens. 2012, 6, 063503-1. [CrossRef]

97. Shukla, J. Predictability in the Midst of Chaos: A Scientific Basis for Climate Forecasting. Science 1998, 282, 728-731. [CrossRef]

98. Vinoj, V.; Rasch, P.J.; Wang, H.; Yoon, J.-H.; Ma, P.-L.; Landu, K.; Singh, B. Short-term modulation of Indian summer monsoon rainfall by West Asian dust. Nat. Geosci. 2014, 7, 308-313. [CrossRef]

99. Tilmes, S.; Hodzic, A.; Emmons, L.K.; Mills, M.J.; Gettelman, A.; Kinnison, D.E.; Park, M.; Lamarque, J.; Vitt, F.; Shrivastava, M.; et al. Climate Forcing and Trends of Organic Aerosols in the Community Earth System Model (CESM2). J. Adv. Model. Earth Syst. 2019, 11, 4323-4351. [CrossRef]

100. He, J.; Zhang, Y.; Glotfelty, T.; He, R.; Bennartz, R.; Rausch, J.; Sartelet, K. Decadal simulation and comprehensive evaluation of CESM/CAM5.1 with advanced chemistry, aerosol microphysics, and aerosol-cloud interactions. J. Adv. Model. Earth Syst. 2015, 7, 110-141. [CrossRef]

101. Wooster, M.J.; Roberts, G.; Perry, G.; Kaufman, Y.J. Retrieval of biomass combustion rates and totals from fire radiative power observations: FRP derivation and calibration relationships between biomass consumption and fire radiative energy release. J. Geophys. Res. Space Phys. 2005, 110. [CrossRef]

102. Roberts, G.; Wooster, M.J.; Lagoudakis, E. Annual and diurnal african biomass burning temporal dynamics. Biogeosciences 2009, 6 , 849-866. [CrossRef]

103. Spracklen, D.V.; Arnold, S.R.; Taylor, C. Observations of increased tropical rainfall preceded by air passage over forests. Nat. Cell Biol. 2012, 489, 282-285. [CrossRef]

104. Fan, J.; Rosenfeld, D.; Zhang, Y.; Giangrande, S.E.; Li, Z.; Machado, L.A.T.; Martin, S.T.; Yang, Y.; Wang, J.; Artaxo, P.; et al Substantial convection and precipitation enhancements by ultrafine aerosol particles. Science 2018, 359, 411-418. [CrossRef] [PubMed]

105. Pöhlker, M.L.; Ditas, F.; Saturno, J.; Klimach, T.; De Angelis, I.H.; Araùjo, A.C.; Brito, J.; Carbone, S.; Cheng, Y.; Chi, X.; et al. Long-term observations of cloud condensation nuclei over the Amazon rain forest-Part 2: Variability and characteristics of biomass burning, long-range transport, and pristine rain forest aerosols. Atmos. Chem. Phys. 2018, 18, 10289-10331. [CrossRef] 
106. Dias, M.A.F.S.; Rutledge, S.; Nobre, C.; Dolman, A.J.; Zipser, E.; Manzi, A.O.; Rocha, H.R.; Plana-Fattori, A.; Sá, L.D.A.; Alvalá, R.C.S.; et al. Cloud and rain processes in a biosphere-atmosphere interaction context in the Amazon Region. J. Geophys. Res. Space Phys. 2002, 107, LBA 39-1. [CrossRef]

107. Wooster, M.J.; Zhang, Y. Boreal forest fires burn less intensely in Russia than in North America. Geophys. Res. Lett. $2004,31$. [CrossRef]

108. Andreae, M.; Rosenfeld, D. Aerosol-cloud-precipitation interactions. Part 1. The nature and sources of cloud-active aerosols. Earth-Sci. Rev. 2008, 89, 13-41. [CrossRef]

109. Monks, P.; Granier, C.; Fuzzi, S.; Stohl, A.; Williams, M.; Akimoto, H.; Amann, M.; Baklanov, A.; Baltensperger, U.; Bey, I.; et al. Atmospheric composition change-Global and regional air quality. Atmos. Environ. 2009, 43, 5268-5350. [CrossRef] 
110. Fröhlich-Nowoisky, J.; Kampf, C.J.; Weber, B.; Huffman, J.A.; Pöhlker, C.; Andreae, M.O.; Lang-Yona, N.; Burrows, S.M.; Gunthe, S.S.; Elbert, W.; et al. Bioaerosols in the Earth system: Climate, health, and ecosystem interactions. Atmos. Res. 2016, 182, 346-376. [CrossRef]

111. Zhong, M.; Saikawa, E.; Liu, Y.; Naik, V.; Horowitz, L.W.; Takigawa, M.; Zhao, Y.; Lin, N.-H.; Stone, E.A. Air quality modeling with WRF-Chem v3.5 in East Asia: Sensitivity to emissions and evaluation of simulated air quality. Geosci. Model. Dev. 2016, 9, 1201-1218. [CrossRef] 